\title{
The Use of C- and L-Band Repeat-Pass Interferometric SAR Coherence for Soil Moisture Change Detection in Vegetated Areas
}

\author{
Brian Barrett*, ${ }^{*}$, Pádraig Whelan ${ }^{1}$ and Ned Dwyer ${ }^{2}$ \\ ${ }^{I}$ School of Biological, Earth and Environmental Sciences, University College Cork (UCC), Distillery Fields, North \\ Mall, Cork, Rep. of Ireland; ${ }^{2}$ Coastal \& Marine Resources Centre (CMRC), University College Cork (UCC), Irish \\ Naval Base, Haulbowline, Cobh, Co. Cork, Rep. of Ireland
}

\begin{abstract}
Soil moisture estimation studies using Synthetic Aperture Radar (SAR) routinely utilise only the amplitude part of the received echo. In this study, repeat-pass C- and L-band interferometric SAR coherence from 2007 - 2009 was evaluated for the detection of surface soil moisture changes in the presence of vegetation using two different approaches. In the first analysis, the association between low coherence and large in situ soil moisture changes was investigated using 24 interferometric pairs and the decorrelation effects due to vegetation and weather were also assessed. Results reveal that, in very few cases soil moisture differences between acquisitions contributed to the signal decorrelation. For the majority of cases, particularly in C-band, the change in vegetation tended to be the predominant source of decorrelation, suppressing the influence of any soil moisture changes. The second analysis applied thresholds to both coherence and intensity data to determine if a coalesced coherence $(\gamma)$ and intensity change $\left(\Delta \sigma^{0}\right)$ approach could improve detection of changes in measured soil moisture content. The aim was to test the usefulness of a $\gamma>0.3$ and $\Delta \sigma^{0}>1.5 \mathrm{~dB}$ thresholding approach to separate the effects of a vegetation change and a soil moisture change on the SAR signal. Results suggest that the approach improves the reliability of the soil moisture change detection although clearly limits the use of available image pairs. These analyses demonstrate the increased information the coherence adds to SAR studies over agricultural areas.
\end{abstract}

Keywords: Synthetic Aperture Radar (SAR), interferometric coherence, soil moisture, change detection.

\section{INTRODUCTION}

Soil moisture exhibits large daily, seasonal and interannual variations, caused primarily by the dynamic processes of precipitation, evapotranspiration and water uptake by plants. Fluctuations in the surface soil moisture result in variations in the latent and sensible heat fluxes, affecting air temperature and humidity and therefore having a significant influence on the short-term climate of a region $[1,2]$. On a global scale, the world's soils contain more carbon than is present in the atmosphere or vegetation [3,4]. As soil moisture content strongly influences the physiological activity of plants and soil microbes $[5,6]$, it exerts a significant control on ecosystem respiration [7] - a major source of carbon to the atmosphere. The corollary of this is that any small changes in ecosystem respiration can cause an ecosystem to switch from being a sink to a source of carbon [8]. Given the fact that there is an exponential decrease in carbon with soil depth, the near soil surface ( upper $20 \mathrm{~cm}$ ) contains the highest concentration of, and also the most active form of carbon within the soil [9-11]. Monitoring the soil moisture content in this layer could potentially improve carbon flux estimates, as well as climate

\footnotetext{
*Address correspondence to this author at the School of Biological, Earth and Environmental Sciences, University College Cork (UCC), Distillery Fields, North Mall, Cork, Rep. of Ireland; Tel: +353 (0) 21 4904553; Fax: +353 (0) 21 4251256; E-mails: brianbarrett@umail.ucc.ie
}

predictions, crop yield forecasts and drought and flood predictions through enhanced hydrological modeling.

Despite its importance, accurate and reliable soil moisture estimation is difficult. As yet there is no means of estimating soil moisture in a spatially consistent and efficient manner. Direct in situ sampling, essentially point measurements, has been the paradigm for soil moisture determination. In the past two decades however, advances in microwave remote sensing technology have progressed to overcome some of the limitations of this traditional approach and offer a viable alternative that is potentially capable of providing regular, spatially distributed measurements of surface soil moisture content [12]. Most studies have concentrated on the relationship of the soil moisture content to the SAR backscattered intensity, usually through forward or inverse modelling. As a result, numerous semi-empirical (e.g. Oh et al., [13], Dubois et al., [14]) and physically-based models (e.g. Fung et al., [15]) have been developed for this purpose. Interferometric synthetic aperture radar (InSAR) [16-19], on the other hand, makes additional use of the phase component of the return signals from two or more coregistered complex SAR images. The interferometric coherence is a measure of the phase correlation between the two SAR images, $S_{l}$ and $S_{2}$ and is defined in equation (1):

$$
\gamma=\frac{\left(S_{1} S_{2}{ }^{*}\right)}{\sqrt{\left(S_{1} S_{1}{ }^{*}\right)\left(S_{2} S_{2}{ }^{*}\right)}}
$$


where $\gamma$ is the (complex) coherence, the brackets $\langle$ ) denote the ensemble average and ${ }^{*}$ denotes the complex conjugate. The phase of $\gamma$ yields the phase difference while the magnitude gives a measure of the quality of the correlation (i.e. the coherence), ranging from 0 (no coherence) to 1 (perfect coherence). Several different factors contribute to the phase decorrelation of the backscattered signal [20] and can be considered as the product of three dominant (statistically independent) contributions:

$|\gamma|=\mid \gamma$ systemNoise $\| \gamma$ Spatiai $\| \gamma$ Temporal $\mid$

The $\left|\gamma_{\text {System Noise }}\right|$ accounts for distortions due both to the SAR processor, e.g. focusing and misregistration, and due to the thermal noise in the receivers (expressed by the signal-tonoise (SNR) ratio of the system). Equation (2) assumes the thermal noise in the receivers is equal. For the repeat-pass configuration, the changes in the viewing geometry or baseline $\left(\left|\gamma_{\text {Spatial }}\right|\right)$ and the changes in the surface scattering centres or their relative orientation between acquisitions $\left(\mid \gamma_{\text {Temporal }}\right)$ are the main factors affecting the interferometric phase [21]. All of these decorrelation sources add noise to the received radar echoes which increase the standard deviation of not only the phase and phase differences inferred, but also that of the final derived products [22].

Despite the influence of these decorrelating factors, InSAR has become a powerful remote sensing technique used in numerous applications from digital elevation model (DEM) generation (e.g. Lanari et al., [23]) to detecting surface displacements, including earthquakes (e.g. Massonnet et al., [24], Peltzer and Rosen [25]), landslides (e.g. Carnec and Fabriol [26], Colesanti and Wasowski [27]), measuring volcanism (e.g. Rosen et al., [28], Lu and Freymueller [29]) and ice-sheet dynamics (e.g. Goldstein et al., [30], Rignot and Kanagaratnam [31], Rignot et al., [32]). Its use for soil moisture estimation however has been less well explored, with few reported studies [33-35]. These studies used C-band coherence to determine areas with limited vegetation and surface roughness dynamics where backscatter intensity changes might be mostly related to soil moisture differences.

Increases in soil moisture content cause an increase in dielectric constant resulting in an increase in radar backscatter intensity [36]. Along with surface roughness, these are the two primary target factors controlling radar intensity. Instances of low coherence and high backscatter intensity change can be an indicator for abrupt surface changes brought about by farming activities such as ploughing and harvesting and also significant changes in crop canopy between acquisitions. In contrast, moderate to high coherence with a significant backscatter change can be inferred as being a result of changing soil moisture [37]. Thus, the coherence can be used to distinguish between a high backscatter intensity change caused by either a soil moisture change or a surface roughness change. Alternatively, the coherence can be used independently by analysing the temporal component of the interferometric phase decorrelation. This can be induced by either a dielectric change or a scatterer geometry change between the two image acquisitions. Similar moisture conditions will have little influence on the coherence, while large changes from wet to dry, or vice versa between acquisitions can have a decorrelation effect as suggested by Luo et al., [38] and Weydahl [39] and demonstrated in laboratory controlled experiments by Nesti et al., [40, 41].

The purpose of this study is to explore the relation between C- and L-band repeat-pass interferometric coherence and soil moisture change using multi-sensor configurations over different crop covers at various times throughout the year. The ENVISAT ASAR sensor, operating at $\mathrm{C}$-band $(5.3 \mathrm{GHz})$ provides multi-mode polarisation and incidence angle capabilities with a temporal revisit time of 35 days. The ALOS PALSAR instrument, the first spaceborne L-band $(1.27 \mathrm{GHz})$ sensor since the SIR-C/XSAR mission to have multi-mode polarimetric capabilities, provides a revisit time of 46 days. The main advantage of using L-band over C-band is its longer wavelength. This allows deeper penetration of vegetated areas, resulting in less temporal decorrelation, as well as increasing the length of the critical baseline, and thus providing more usable interferometric pairs. The study objectives can be divided into three sections: a) to investigate whether low coherence correlates with large changes in measured soil moisture content; b) to assess the influence of weather conditions and vegetation height on the coherence; and, c) to perform a combined coherence and intensity change analysis to determine whether areas with a moderate to high coherence and change in intensity are linked to changes in soil moisture and not changes in scatterer geometry. The key innovation in objective c) is the use of a lower coherence threshold $(\gamma>$ 0.3 rather than $\gamma>0.7$, as in Wegmüller [33]) to include vegetated fields in the analysis and allow for the longer temporal baseline between acquisitions. Most of the published literature using the $\gamma>0.7$ threshold used one-day interval ERS 1/2 Tandem coherence and few studies have been carried out using long repeat-pass intervals, especially at L-band.

\section{STUDY AREA AND DATASETS}

\subsection{Study Area}

The study area is located on Great Island (Cobh), approximately $20 \mathrm{~km}$ east of Cork City, Ireland (Lat. 51 ${ }^{\circ}$ $52^{\prime} \mathrm{N}$, Long. $-8^{\circ} 16^{\prime} \mathrm{E}$ ) (see Fig. 1). The area has a temperate climate with annual average rainfall of between $1100 \mathrm{~mm}$ and $1250 \mathrm{~mm}$ and generally high relative humidity, averaging $\sim 90 \%$ throughout the year. As can be seen in Fig. (1), the area is predominantly agricultural. Areas in dark green relate to coniferous forest. Grassland and some agricultural areas are a lighter shade of green while light brown signifies harvested cereal fields. The delineated polygons indicate the selected test fields. The field texture and crop cover during each growing season are specified in Table 1 . The effects of soil texture on the SAR backscatter [42] were not considered in this study.

\subsection{Field Observations}

Simultaneous ground measurements were carried out on the test fields for all SAR acquisitions. The field measurements consisted of volumetric soil moisture (at depths of $0-6 \mathrm{~cm}$ with $\geq$ three replicates at each sampling site), crop height and crop phenological stage. All fields were photographed and qualitatively described and fieldwork carried out within 4 hours of the satellite overpass. The soil 


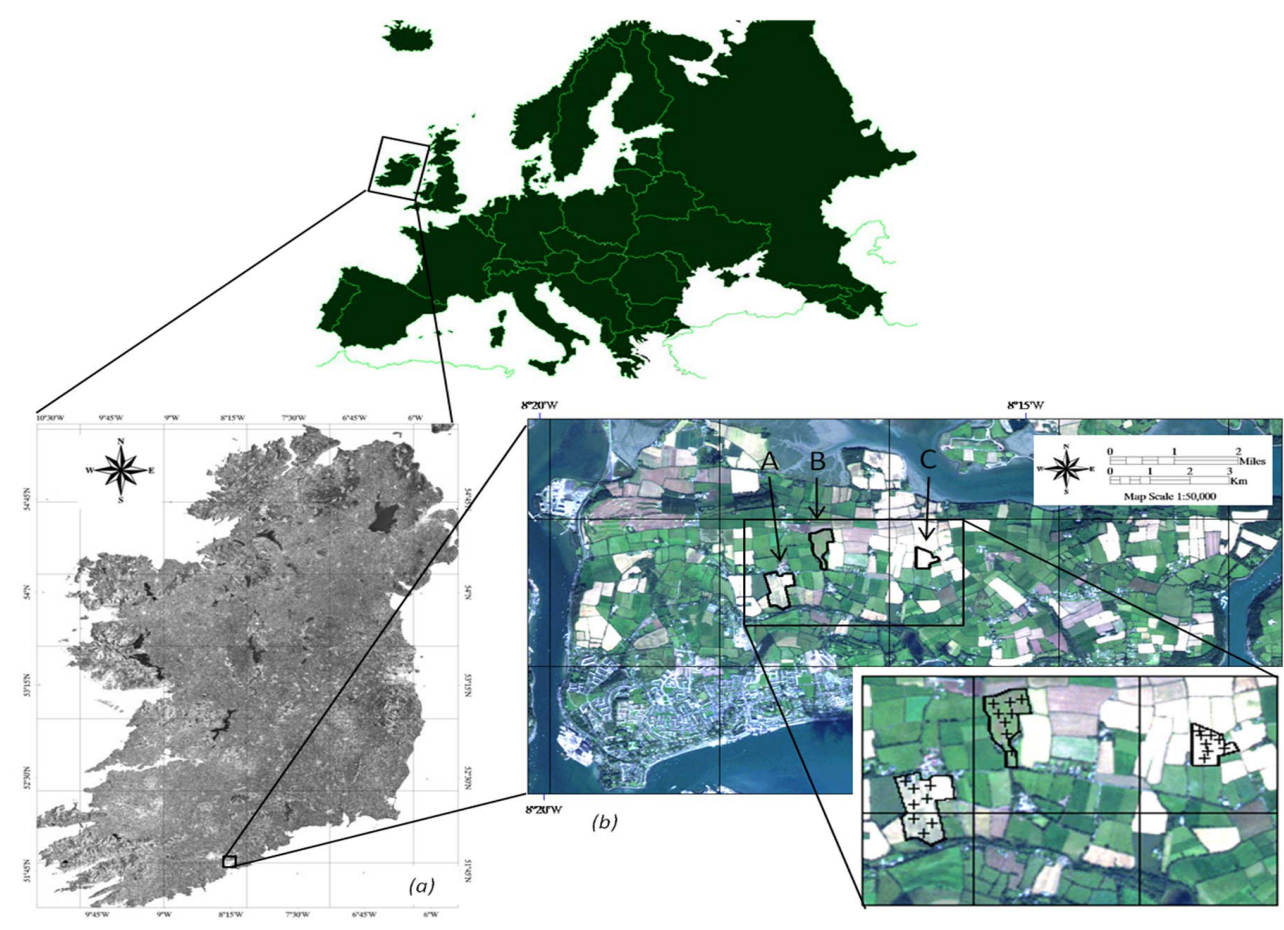

(a)

(b)

Fig. (1). Map of Europe showing (a) an ASAR Wide Swath image of Ireland and (b) an ALOS AVNIR-2 image (band combination 3:2:1) acquired $5^{\text {th }}$ October 2008 displaying the study fields (delineated) and sampling site locations within each field (plus symbols) located at Great Island, Cork, Ireland.

Table 1. Crops Grown for Each Season in Each Field

\begin{tabular}{|l|c|c|c|c|}
\hline Field ID. & $\mathbf{2 0 0 7 - 2 0 0 8}$ & $\mathbf{2 0 0 8 - 2 0 0 9}$ & $\mathbf{2 0 0 9 - 2 0 1 0}$ & Texture \\
\hline \hline A & Spring Barley & Spring Barley & Spring Barley \& Potato & Silty Clay \\
\hline B & - & Potato & Spring Barley & Clay Loam \\
\hline C & Potato & Spring Barley & Potato & Silty Loam \\
\hline
\end{tabular}

moisture measurements were acquired by using both a Stevens Hydraprobe $®$ dielectric sensor and thermogravimetric methods with a sampling density of eight location points per field. The selected fields were chosen to ensure different crop covers and also due to their proximity to one another to facilitate ground sampling. Mean soil moisture and crop height values along with their standard error are displayed in Fig. (2). As can be seen, the measured soil moisture values cover a dynamic range, from little or no moisture to relatively high moisture between acquisitions. The crop heights reach a maximum in July and a minimum in March for each year and display quite similar trends in increases and decreases.

\subsection{InSAR Pairs}

The SAR data selection process has a significant influence on the resulting interferometric products and the selection criteria vary according to the specific needs of each investigation. The primary and most straightforward concern is the initial availability of the data. Not all spaceborne SAR instruments operate in a continuous, spatially and temporally consistent manner. While, on the one hand, variable polarisations, incidence angles and resolutions bring about greater opportunity, in terms of the ability to characterise backscatter from various objects and surfaces, they result in inconsistent and often limited data archives that are insufficient for operational interferometric purposes. The mode of operation for ALOS is different from its predecessors in that the Japan Aerospace Exploration Agency (JAXA) have implemented a pre-launch systematic acquisition strategy, whereby the sensor mode, geographical region and acquisition timing have been fixed for the duration of the mission, thereby providing long-term, systematic and repetitive observations over the whole Earth [43].

Data availability is further constrained by the baseline criteria. When the perpendicular component of the baseline between the master and slave orbit increases beyond a limit known as the critical effective baseline $\left(B_{\text {CRIT }}\right)$ (i.e. the maximum horizontal separation permitted between the two satellite overpasses), no phase information is preserved, coherence drops to zero and interferometry is not possible [17]. The critical baseline is calculated using:

$B_{C R T}=\frac{\lambda \operatorname{Rtan} \theta}{2 R_{R}}$ 

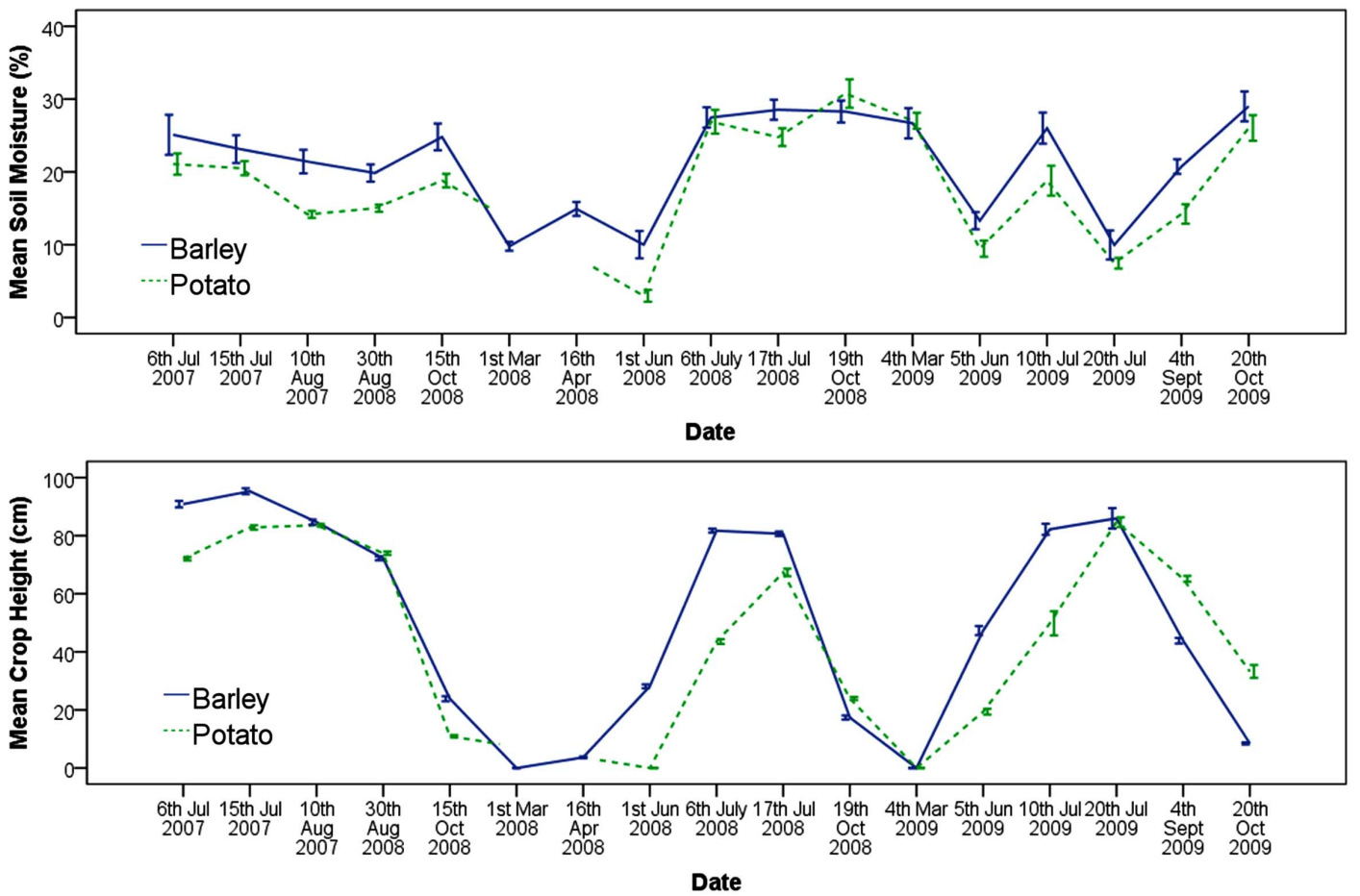

Fig. (2). Time series of in situ soil moisture and crop height from barley (solid line) and potato (dashed line) fields from July 2007 to October 2009. Error bars represent one standard error.

Table 2. Comparison of Critical Baselines

\begin{tabular}{|l|c|c|c|}
\hline Sensor & Bandwidth & Incidence Angle & Critical Baseline (m) \\
\hline \hline ENVISAT ASAR (I1) & $16 \mathrm{MHz}$ & $\sim 18.7^{\circ}$ & $\sim 745$ \\
\hline ALOS PALSAR FBD & $14 \mathrm{MHz}$ & $\sim 38.7^{\circ}$ & $\sim 6,550$ \\
\hline ALOS PALSAR FBS & $28 \mathrm{MHz}$ & $\sim 38.7^{\circ}$ & $\sim 13,100$ \\
\hline
\end{tabular}

where $\lambda$ is the wavelength, $R$ is the range distance, $R_{R}$ is the range pixel spacing and $\theta$ is the incidence angle. Table 2 shows the calculated critical baselines for each sensor and data mode used in this study. The longer wavelength of the PALSAR data increases the critical baseline resulting in more usable interferometric pairs. Table 3 specifies the characteristics of the 24 selected data pairs for this study. The data include acquisitions from both the non-growing and growing seasons of two consecutive years. All PALSAR Fine Beam Dual (FBD) polarisation (HH/HV) and Fine Beam Single (FBS) polarisation $(\mathrm{HH})$ acquisitions have an incidence angle of $\sim 38^{\circ}$ and all of the ASAR Alternating Polarisation (APS) (HH/HV) mode acquisitions were acquired with an incidence angle of $\sim 19^{\circ}$. The pixel spacing for the FBS data is $4.68 \mathrm{~m}$ in range and $3.17 \mathrm{~m}$ in azimuth direction, compared to $9.36 \mathrm{~m}$ in range and $3.17 \mathrm{~m}$ in azimuth for the FBD mode. The APS data have a sample spacing of $7.80 \mathrm{~m}$ in range and $4.05 \mathrm{~m}$ in azimuth.

The length of time between successive (and suitable same track and frame) orbits varied from 35 to 105 days (one, two and three repeat-cycles) for ASAR and 46 to 138 days for PALSAR. All ASAR data were acquired during descending passes ( 11:00 UTC) from July 2007 to July 2009. ASAR InSAR pairs with perpendicular baselines shorter than $200 \mathrm{~m}$ were chosen to maximise coherence and minimise the topographic contribution. All the PALSAR datasets were acquired during ascending passes ( 22:45 UTC) from July 2007 to October 2009. Due to the longer critical baseline offered by PALSAR, a larger selection of InSAR pairs from this sensor could be used. A maximum temporal baseline of 138 days and the shortest perpendicular baselines were chosen. The long baseline June-July 2008 FBD pair $(3835 \mathrm{~m})$, was included for comparative purposes with the ASAR June-July 2008 pair.

\subsection{Meteorological Data}

The degree of coherence can depend on the weather conditions at the time of acquisition (e.g. a change in wind conditions at either acquisition could change the scatterer locations and thereby reduce the coherence). Hourly meteorological recordings of precipitation, temperature, maximum wind speed and relative humidity, taken from two nearby Met Éireann (Irish Meteorological Service) stations at Cork airport (Lat $51^{\circ} 50^{`} \mathrm{~N}$, Long $-08^{\circ} 29^{\circ} \mathrm{E}$ ) and Roche's point (Lat $51^{\circ} 46^{`} \mathrm{~N}$, Long- $\left.08^{\circ} 15^{`} \mathrm{E}\right)$ were used in this analysis to determine their influence, if any, on the estimated coherence. The mean value between these two stations measurements nearest the time of acquisition is given in Table 4. The precipitation values are the accumulated precipitation values for the 72 hours prior to the time of acquisition. 
Table 3. Summary of Selected ASAR and PALSAR Interferometric Pairs. $\perp$ Baseline Refers to the Perpendicular Baseline (Spatial Baseline) Between Master and Slave Orbits

\begin{tabular}{|c|c|c|c|c|c|c|}
\hline Pair \# & Master & Slave & Day diff & $\perp$ Baseline (m) & Track/ Frame & Polarisation \\
\hline & ASAR APS & & & & & \\
\hline 2. & $06 / 07 / 2007$ & $10 / 08 / 2007$ & 35 & 75 & $352 / 2547$ & $\mathrm{HV}$ \\
\hline 3. & $01 / 06 / 2008$ & $06 / 07 / 2008$ & 35 & 187 & $80 / 2558$ & $\mathrm{HH}$ \\
\hline 5. & $06 / 07 / 2008$ & $19 / 10 / 2008$ & 105 & 52 & $80 / 2558$ & $\mathrm{HH}$ \\
\hline 6. & $06 / 07 / 2008$ & $19 / 10 / 2008$ & 105 & 52 & $80 / 2558$ & $\mathrm{HV}$ \\
\hline \multirow[t]{2}{*}{7.} & 05/06/2009 & $10 / 07 / 2009$ & 35 & 65 & $352 / 2555$ & $\mathrm{HH}$ \\
\hline & PALSAR FBD & & & & & \\
\hline 11. & $15 / 7 / 2007$ & $30 / 8 / 2007$ & 46 & 838 & $3 / 1030$ & HV \\
\hline 12. & $30 / 8 / 2007$ & $15 / 10 / 2007$ & 46 & 537 & $3 / 1030$ & $\mathrm{HH}$ \\
\hline 13. & $30 / 8 / 2007$ & $15 / 10 / 2007$ & 46 & 537 & $3 / 1030$ & $\mathrm{HV}$ \\
\hline 14. & $01 / 06 / 2008$ & $17 / 07 / 2008$ & 46 & 3835 & $3 / 1030$ & $\mathrm{HH}$ \\
\hline 15. & $01 / 06 / 2008$ & $17 / 07 / 2008$ & 46 & 3835 & $3 / 1030$ & $\mathrm{HV}$ \\
\hline 16. & $20 / 07 / 2009$ & $04 / 09 / 2009$ & 46 & 604 & $3 / 1030$ & $\mathrm{HH}$ \\
\hline 17. & $20 / 07 / 2009$ & 04/09/2009 & 46 & 604 & $3 / 1030$ & $\mathrm{HV}$ \\
\hline 18. & $20 / 07 / 2009$ & $20 / 10 / 2009$ & 92 & 1064 & $3 / 1030$ & $\mathrm{HH}$ \\
\hline 22. & $1 / 3 / 2008$ & $1 / 6 / 2008$ & 92 & 604 & $3 / 1030$ & $\mathrm{HH}$ \\
\hline 23. & $16 / 4 / 2008$ & $1 / 6 / 2008$ & 46 & 419 & $3 / 1030$ & $\mathrm{HH}$ \\
\hline 24. & $4 / 3 / 2009$ & $20 / 7 / 2009$ & 138 & 531 & $3 / 1030$ & $\mathrm{HH}$ \\
\hline
\end{tabular}

\section{METHODOLOGY}

\subsection{SAR Preprocessing}

The SAR data were selected and processed to minimise the influence of the system and spatial decorrelation factors discussed in section 1 , so that the remaining source of coherence loss is due primarily to temporal decorrelation. Interferometric processing for all the Single Look Complex (SLC) datasets was performed using SARscape ${ }^{\circledR}$ software within an ENVI ${ }^{\circledR}$ environment. The precise satellite orbits were provided by the European Space Agency (ESA) for the ASAR data as DORIS (Doppler Orbitography and Radiopositioning Integrated by Satellite) files and by JAXA as precise state vectors contained in the leader file of the PALSAR data. The SLC images were first co-registered to sub-pixel level $\left(1 / 10^{\text {th }}\right.$ pixel accuracy), ensuring the phase differences being measured were for the same target area.
The interferograms were subsequently generated and spectral shift and common Doppler bandwidth filtering applied to minimise the effects of the baseline geometry on the coherence estimation [44]. Range and azimuth multi-looking of 1 and 6 for ASAR, 1 and 4 for PALSAR FBD and 1 and 3 for PALSAR FBS was performed to improve the phase and coherence estimates [45]. As the data were acquired from different imaging geometries, the images were processed in different sets, according to their acquisition mode and satellite track. A master image was chosen in each set and all other images were co-registered to the same common slant range geometry. The seven ASAR and eleven PALSAR intensity images were speckle filtered in separate sets using a 3x3 window size De Grandi multi-temporal filter [46] and radiometrically and geometrically calibrated and converted to $\mathrm{dB}$. The backscatter images and corresponding coherence images were geocoded to $10 \mathrm{~m} \times 10 \mathrm{~m}$ (PALSAR FBS), $15 \mathrm{x}$ 
Table 4. Meteorological Conditions at Time of Image Acquisitions

\begin{tabular}{|c|c|c|c|c|c|}
\hline Image \# & Date & Temp $\left({ }^{\circ} \mathrm{C}\right)$ & $\begin{array}{l}\text { Accumulated } 3 \text { Day Precip } \\
\text { (mm) }\end{array}$ & Relative Humidity (\%) & $\begin{array}{l}\text { Wind Speed } \\
\text { (Knots) }\end{array}$ \\
\hline & ASAR APS & & & & \\
\hline 1. & $06 / 07 / 2007$ & 16.0 & 6.5 & 63 & 18.5 \\
\hline 2. & $10 / 08 / 2007$ & 14.4 & 1.2 & 95 & 7 \\
\hline 3. & $01 / 06 / 2008$ & 18.3 & 1.8 & 57 & 3 \\
\hline 5. & $19 / 10 / 2008$ & 12.3 & 0.4 & 95 & 23 \\
\hline 6. & $05 / 06 / 2009$ & 14.2 & 0 & 80 & 7.5 \\
\hline \multirow[t]{2}{*}{7.} & $10 / 07 / 2009$ & 13.7 & 4.7 & 95 & 6 \\
\hline & PALSAR FBD & & & & \\
\hline 10. & $15 / 10 / 2007$ & 13.4 & 1.2 & 98 & 12.5 \\
\hline 11. & $01 / 06 / 2008$ & 13.1 & 1.4 & 94 & 4 \\
\hline 12. & $17 / 07 / 2008$ & 14.6 & 0.2 & 91 & 7.5 \\
\hline 13. & $20 / 07 / 2009$ & 13.1 & 0.1 & 96 & 7 \\
\hline 14. & 04/09/2009 & 10.2 & 15.3 & 91 & 7.5 \\
\hline \multirow[t]{2}{*}{15.} & $20 / 10 / 2009$ & 11.6 & 11.6 & 82 & 16 \\
\hline & PALSAR FBS & & & & \\
\hline 16. & $1 / 3 / 2008$ & 4.4 & 13.5 & 86 & 9.5 \\
\hline 17. & $16 / 4 / 2008$ & 8.3 & 0 & 73 & 17.5 \\
\hline
\end{tabular}

$15 \mathrm{~m}$ (PALSAR FBD \& PALSAR FBD2FBS mixed mode) and $25 \mathrm{~m} \times 25 \mathrm{~m}$ (ASAR APS) pixel size using several ground control points and an Ordnance Survey of Ireland (OSi) $10 \mathrm{~m}$ DEM and projected into the Irish National Grid projection [47].

\subsection{Analysis of Temporal Decorrelation}

In-situ soil moisture measurements were compared to the estimated interferometric coherence values for both crops separately. The relationship between the coherence and measured surface soil moisture change at each sampling location was assessed for both crops using a correlation analysis. Similarly, the influence of various meteorological variables on the coherence was investigated using a correlation analysis and the impact of the crop height (recorded at the time of image acquisition) on the coherence was qualitatively assessed. All statistical analyses were carried out using IBM® SPSS $® 17$ and all $P$-values are twotailed unless otherwise noted.

\subsection{Intensity Change and Coherence Analysis}

To determine whether combined backscatter intensity and coherence thresholding strengthened the determination of delta soil moisture, three different analyses were carried out: (i) all data that only meets the $\Delta \sigma^{0}>1.5 \mathrm{~dB}$ correlated with $\Delta m_{v}$, (ii) all data that only met the $\gamma>0.3$ requirement correlated with $\Delta m_{v}$, (iii) all data that met the $\Delta \sigma^{0}>1.5$ and $\gamma$ $>0.3$ requirement correlated with $\Delta m_{v}$. The coherence was used, in this instance, to select the areas where the target geometry remained consistent between acquisitions and the $\Delta \sigma^{0}$ could be used to retrieve the soil moisture change. The method is similar to that in [33], albeit with a lower coherence threshold to take into account the vegetated surfaces and the generally lower coherence associated with long-interval repeat-pass acquisitions.

\section{RESULTS AND DISCUSSION}

\subsection{Decorrelation and Soil Moisture Change}

The mean coherence values for all datasets are plotted against their corresponding acquisition dates for both crop types in Fig. (3). As expected, a generally low overall coherence was observed. The longer temporal baseline pairs (two and-three repeat cycles) showed a surprisingly reasonable coherence, relative to the one-repeat cycle pairs. HV coherence pairs were also rather highly correlated, considering the lower signal-to-noise ratio and increased volume scattering effects. A series of scatter plots (Fig. 4) were generated to first determine, qualitatively, whether any correlation existed between low coherence values and changes in surface soil moisture content $\left(\Delta m_{v}\right)$. The plots show considerable variability with some (e.g. Fig. (4a) and (d)) suggesting a possible linkage between low coherence $(\gamma$ 

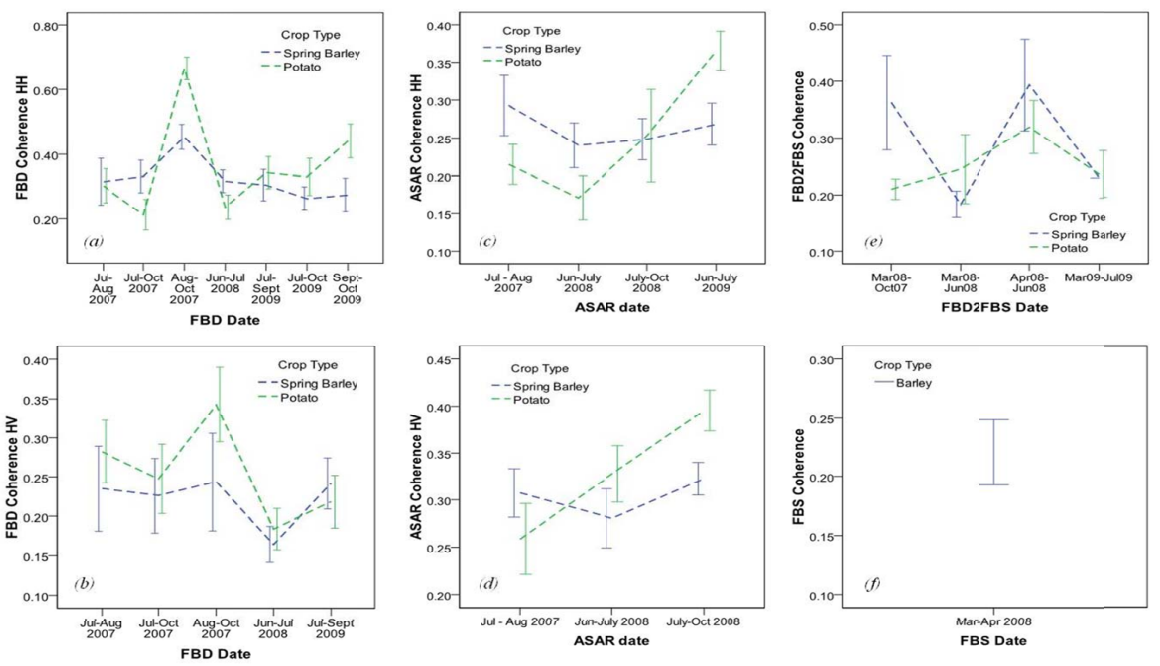

Fig. (3). Mean coherence for PALSAR FBD (a-b), ASAR (c-d), PALSAR FBD2FBS (e) and FBS (f) pairs for both crop types in HH and HV polarisation. Error bars represent one standard error.
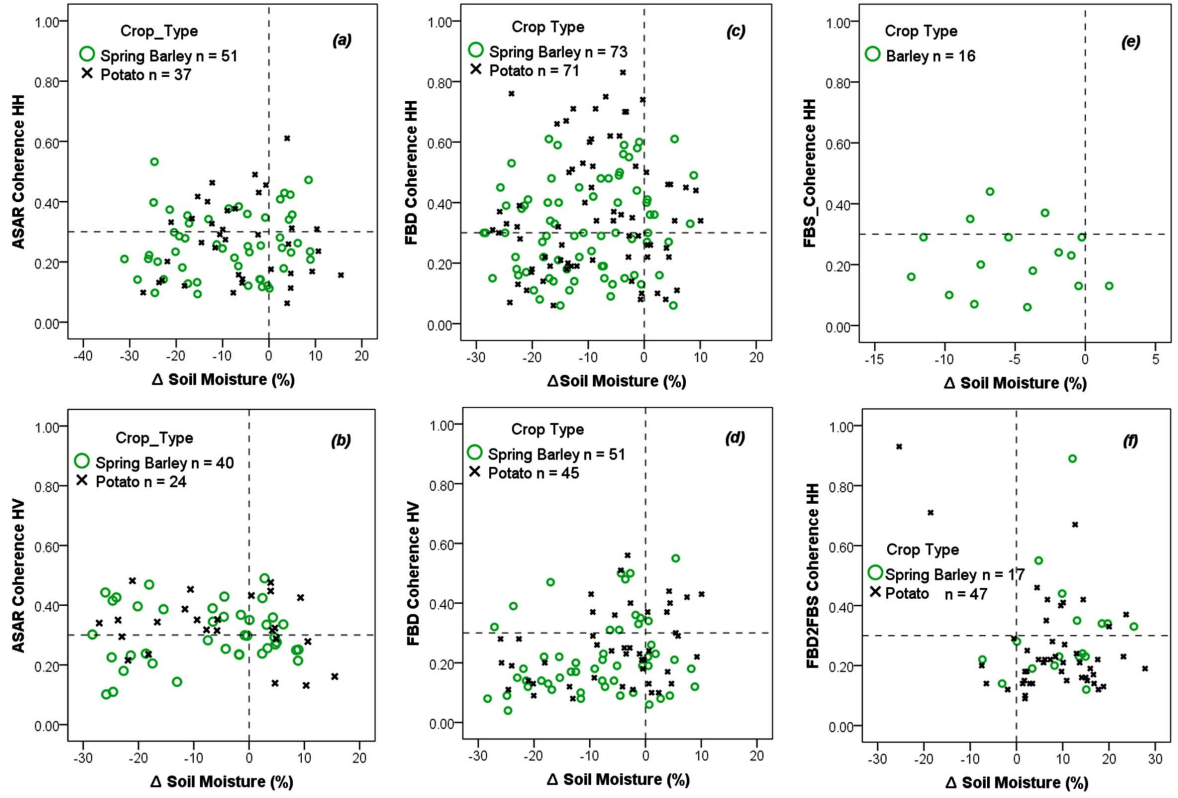

Fig. (4). (a) ASAR HH coherence, (b) ASAR HV coherence, (c) PALSAR FBD HH coherence, (d) PALSAR FBD HV coherence, (e) PALSAR FBS coherence and (f) PALSAR FBD2FBS coherence as a function of field measured soil moisture change between interferometric pairs.

$<0.3$ ) and large changes in soil moisture between the master and slave acquisitions. There are, however, numerous data points, the most notable of which is displayed in Fig. (4c) indicating instances where large soil moisture changes did not correspond with low coherence. To investigate the dependency of decorrelation upon soil moisture changes, plots of low coherence $(\gamma<0.3)$ as a function of soil moisture change $\left(\Delta m_{v}\right)$ were generated for each interferometric pair for both crop cover types (Fig. 5). The FBD HH Aug-Oct 2007 pair is not displayed due to a lack of data points satisfying the $\gamma<0.3$ criterion.

The single-pair correlation analysis showed that the association between soil moisture change and coherence was highly variable. A large spread is observed in most plots and no general trend across the datasets could be established.
Several pairs showed very little change in the soil moisture state between acquisitions (e.g. Fig. (5a), (b), (e), (f), (k), $(\mathbf{m}),(\mathbf{p}),(\mathbf{r})$, and $(\mathbf{v}))$ and unsurprisingly displayed no link between decorrelation and $\Delta m_{v}$. The determination coefficients $\left(\mathrm{R}^{2}\right)$, expressing the proportion of coherence variance explained by the soil moisture change for each plot, are presented in Table 5. Using four or fewer subjects to estimate the strength of association between the coherence and soil moisture change carries little merit and tends to result in model over-fitting. Consequently, pairs with degrees of freedom $(d f) \leq 2$ were discarded leaving 32 out of an original 42 datasets, of which only eleven displayed soil moisture changes of $>10 \%$ between acquisitions. The majority of the pairs in Table 5 revealed no relationship between the changes in soil moisture and low coherence, with $\mathrm{R}^{2}$ val- 


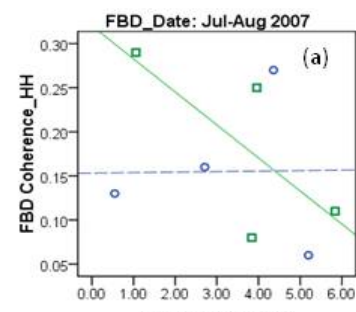

$\Delta$ Soil Moisture (\%)
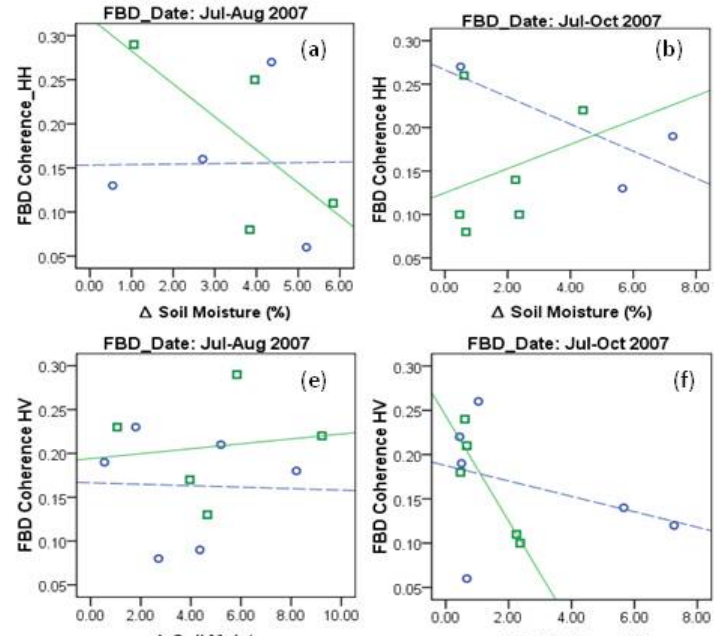

$\triangle$ Soil Moisture $(\%)$

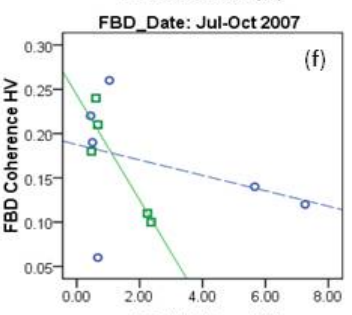

$\triangle$ Soil Moisture (\%)

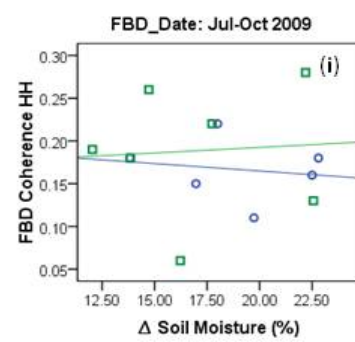

$\Delta$ Soil Moisture $(\%)$

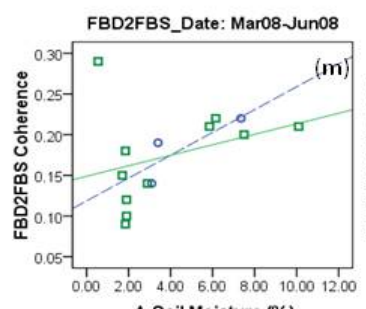

$\Delta$ Soil Moisture $(\%)$
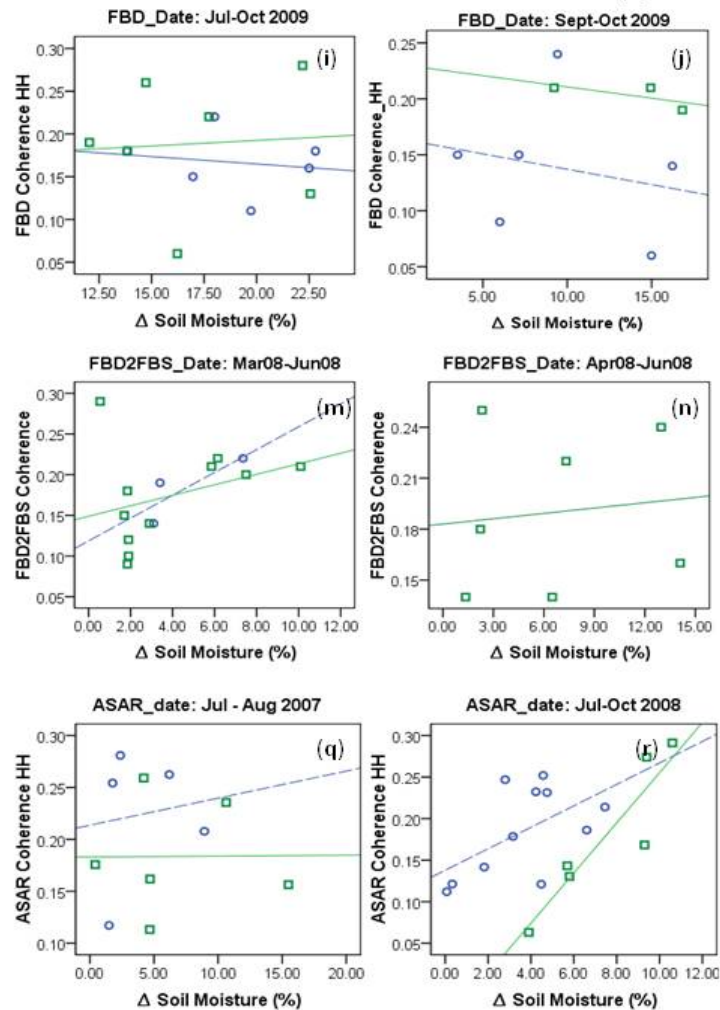

$\Delta$ Soil Moisture $(\%)$

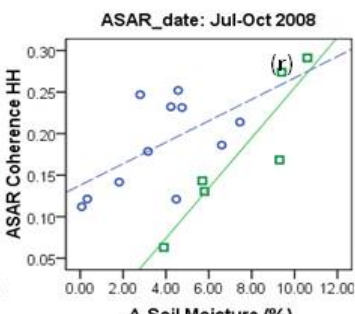

$\Delta$ Soil Moisture $(\%)$
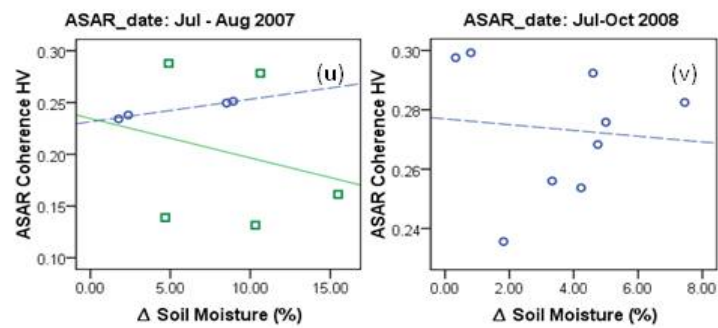

Spring Barley

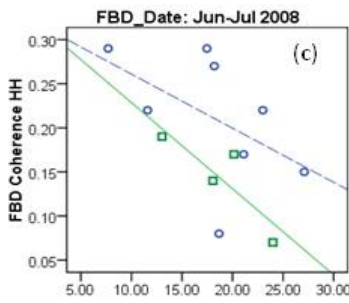

$\triangle$ Soil Moisture $(\%)$

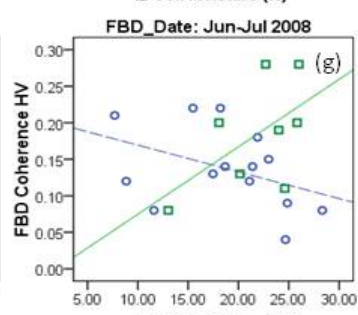

$\triangle$ Soil Moisture (\%)

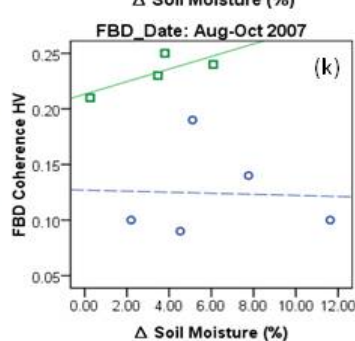

(k)
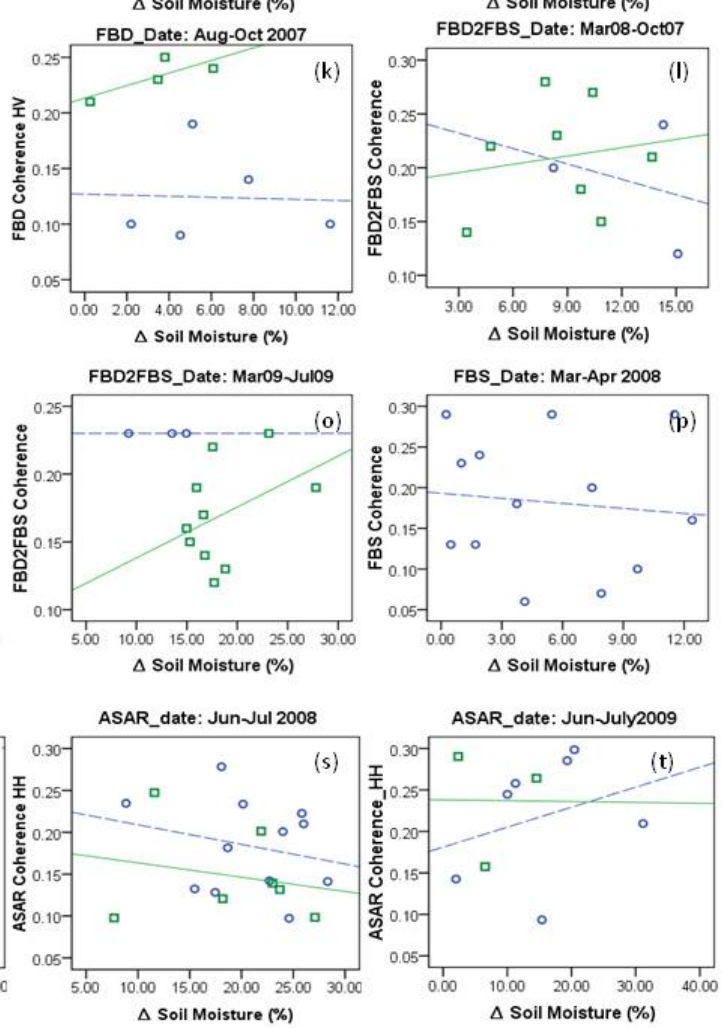

ASAR_date: JunJul 2008

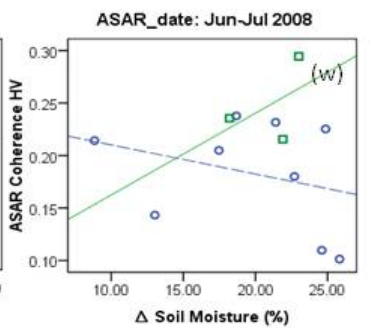

$\Delta$ Soil Moisture $(\%)$

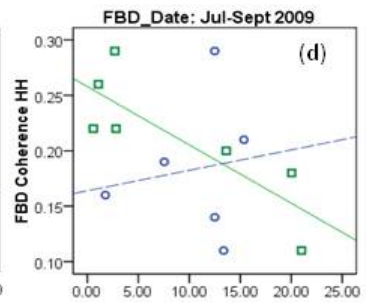

$\triangle$ Soil Moisture $(\%)$

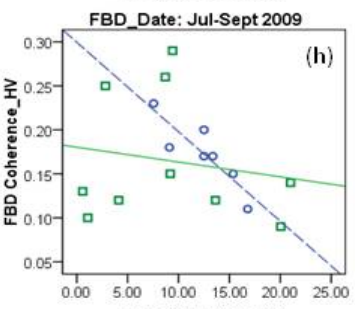

$\triangle$ Soil Moisture (\%)

Potato
Spring Barley $>$ Potato

Fig. (5). Plots of PALSAR L-band and ASAR C-band coherence $<0.3$ as a function of $\Delta$ soil moisture for each image pair.

ues close to zero. Four datasets, one C-band, and three Lband displayed significant correlations. The highest L-band $\mathrm{R}^{2}$ values signify that $68 \%$ of the variance in Jul-Sept 2009
HH, 84\% in Jul-Oct 2007 HV and 77\% in Jul-Sept 2009 HV coherence could be explained by an increasing change in soil moisture content. 
Table 5. Computed Statistics and Model Parameters for the Association between $\triangle$ Soil Moisture and Coherence $<0.3$. The C-HV Jul - Oct 2008 (Potato) Pair, L-HH Aug - Oct 2008 (barley \& Potato) Pair, FBD2FBS Apr08 - Jun08 (Barley) Pair and the FBD2FBS Mar09 - Jul 09 (Barley) Pair were Not Included Due to an Insufficient Amount of Data Points Satisfying the $\gamma<0.3$ criteria to Run the Analysis. The Pairs in Italics Signify the 11 Pairs with $\Delta m_{v}>10 \% . D f$ is the Degrees of Freedom (n-2).

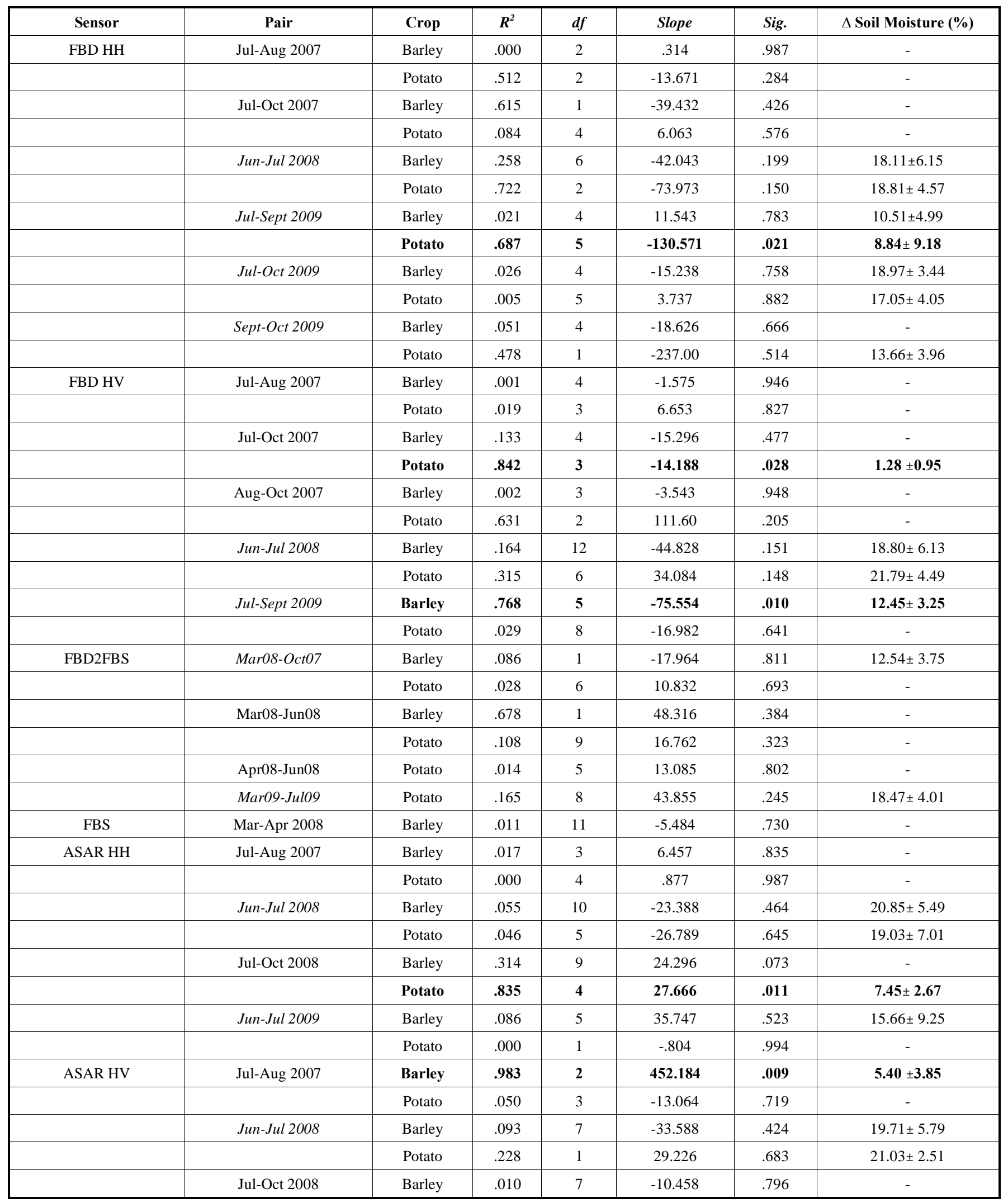



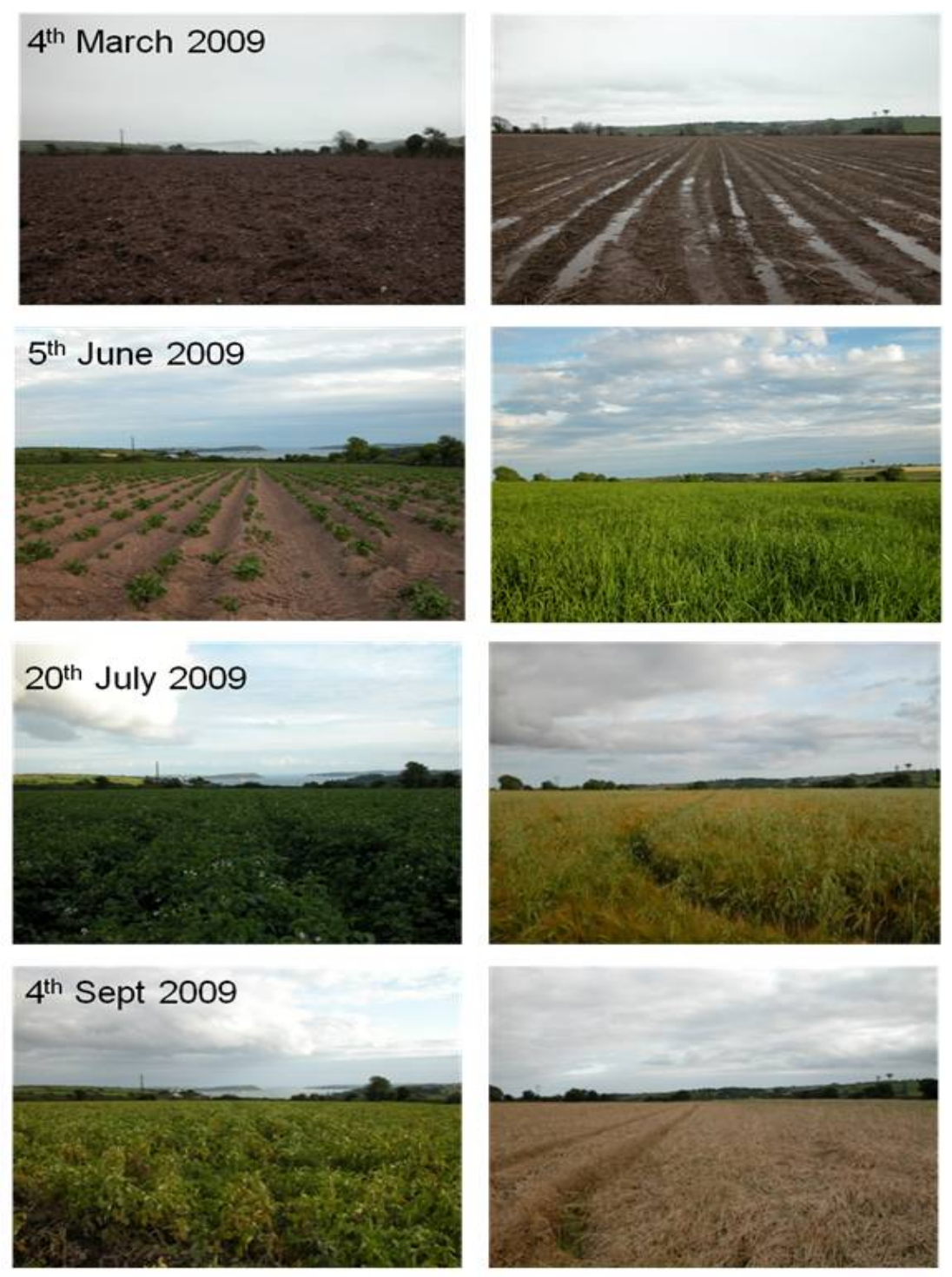

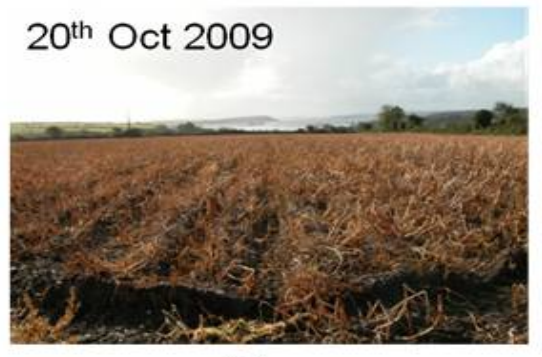

(a)

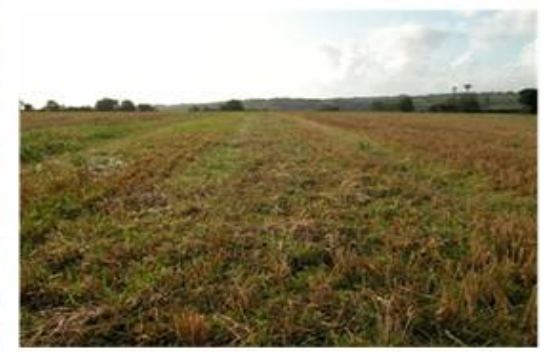

(b)

Fig. (6). Ground photographs showing the temporal development of the potato $(a)$ and barley crop $(b)$ on the day of satellite overpass from $4^{\text {th }}$ March - $20^{\text {th }}$ Oct 2009.

The reliability of the Jul-Oct 2007 L-HV value is doubtful, as the measured mean $\Delta m_{v}$ was less than $2 \%$ between acquisitions. It is likely the observed correlation between the two variables was due to the action of one or more independent variables. The Jul-Oct $2008 \mathrm{C}-\mathrm{HH}$ significant $\mathrm{R}^{2}$ indicates a link between an increasing coherence and increasing soil moisture change, a relation that would not exist. As the measured mean $\Delta m_{v}$ of less than $8 \%$ between acquisitions was not large enough to have a considerable impact on the coherence, it is again apparent that the correlation was influenced by one or more different variables.
Given the long acquisition intervals, the relatively dense crop canopies and the fact the transitions from wet to dry and vice versa were not observed in each pair, it can be argued that the displacement of the scatterer centers due to the growth of the crop or from ploughing and harvesting events may be the primary explanation for the decorrelation. Similarly, certain meteorological parameters at the time of acquisition can impact on the coherence and contribute to the observed decorrelation. To evaluate these associations, both the influence of the weather and the presence of the vegetation on the temporal decorrelation were investigated. 


\subsubsection{Meteorological Effects on the Temporal Decorrelation}

A correlation analysis was performed using the difference in wind speed, temperature, precipitation and relative humidity, recorded at both acquisition dates for each interferometric pair. This was carried out to determine whether certain meteorological variables had a decorrelation effect on the selected image pairs. Table 4 displays the values of these variables recorded closest to the time of overpass. The highest correlation coefficients from all datasets were found for the ASAR HH pairs, where differences in wind speed $(n=45$, $\mathrm{R}=-0.47, \mathrm{p}=0.001)$, temperature $(\mathrm{n}=45, \mathrm{R}=-0.30, \mathrm{p}=0.04)$ and precipitation $(\mathrm{n}=45, \mathrm{R}=-0.30, \mathrm{p}=0.04)$ suggest a limited contribution towards the temporal decorrelation observed over the fields with potato crop cover only. The PALSAR FBD data also displayed a weak correlation $(n=71, R=-0.36$, $\mathrm{p}=0.002$ ) between precipitation differences and $\mathrm{HH}$ coherence for the potato crop cover. It can be seen from Table $\mathbf{4}$ that the highest wind speed, temperature and precipitation values were all recorded on ASAR acquisition dates. From the reported negative correlations, there is evidence that strong winds (e.g. 23 knots on 19/10/2008), high accumulated rainfall (e.g. $47.2 \mathrm{~mm}$ on $06 / 07 / 2008$ ) and highest recorded temperatures (e.g. $18.3^{\circ} \mathrm{C}$ on $01 / 06 / 2008$ ) on either acquisition date can be linked to reduced coherence, as found in studies by Smith et al., [48], Zebker et al., [49] and Drezet and Quegan [50].

Since C-band is more sensitive to scatterers on the order of its wavelength, L-band coherence should be less sensitive to the effects of wind as the scattering elements are larger and more stable. No correlation was found between L-band coherence and wind speeds in this study and no significant correlations between any of the meteorological variables and coherences were observed in the remaining ASAR HV and PALSAR FBD HV pairs or in the FBS and FBD2FBS datasets, for either potato or barley crop cover. Thus, a considerable proportion of the variance in the coherence remained unaccounted for.

\subsubsection{Vegetation Effects on the Temporal Decorrelation.}

The presence of vegetation over the soil surface adds considerable complexity to measuring surface soil moisture conditions using SAR [51]. The return signal from vegetation varies with frequency and polarisation and is dependent largely on the size and geometry of the various plant components and also the roughness and moisture content of the underlying soil surface. Shorter wavelengths are scattered mostly by the leaves in the surface canopy, whereas longer wavelengths can penetrate deeper into the canopy and interact with the underlying soil surface. As the crop grows, it screens more of the ground and a greater part of the incident radar energy is backscattered from the vegetation than from the underlying soil surface, causing the signal to decorrelate more rapidly. The percentage crop cover and vigour also influence the degree of coherence [37]. Many studies have shown the interferometric coherence to be related to biophysical parameters of forests [52-55] and agricultural crops [56-58] where increasing crop height provides progressively lower coherence. The polarisation of the transmitted wave dictates which components of the vegetation and soil contribute to the total amount of energy scattered back to the sensor. The co-polarised signal returns tend to penetrate the vegetation canopy to a greater extent than cross-polarised radiation which tends to be dominated by returns from volume scattering within the crop canopy (causing depolarisation).

Farming activity and crop growth between the two acquisitions disturbed the scatterers and drastically reduced the coherence. Fig. (2) displays the temporal evolution of the crop heights throughout the whole study period and Fig. (6) shows the temporal development of two of the fields from $4^{\text {th }}$ March 2009 to $20^{\text {th }}$ Oct 2009 . As is evident, the crop condition at the various acquisition dates was not similar and therefore height and density variations occur that influence the coherence. The Jul-Oct $2007 \mathrm{~L}-\mathrm{HV}$ potato crop height decreased from an average $82.81 \pm 3.39 \mathrm{~cm}$ to an average $10.95 \pm 1.94 \mathrm{~cm}$ during the 92 day acquisition interval. This drastic change in surface geometry, coupled with the small change in mean measured soil moisture is the most likely rationale behind the observed decorrelation. Similarly, the Jul-Oct 2008 C-HH potato crop height decreased from 43.52 $\pm 3.83 \mathrm{~cm}$ to $23.95 \pm 2.35 \mathrm{~cm}$ between acquisitions. Again, given the long acquisition interval (105 days), the observed decorrelation is more than likely due to the complete change in scattering geometry of the potato crop.

The Jul-Sept $2009 \mathrm{~L}-\mathrm{HH}$ pair which displayed an $\mathrm{R}^{2}$ of 0.68 between low coherence and $\Delta m_{v}$ (mean $8.84 \pm 9.18 \%$ ) also experienced a decrease in average potato crop height from $84.6 \pm 7.53 \mathrm{~cm}$ to $65.1 \pm 4.68 \mathrm{~cm}$ between $20^{\text {th }}$ July and $4^{\text {th }}$ Sept 2009. Similarly, the barley height for the Jul-Sept 2009 L-HV pair displaying an $\mathrm{R}^{2}$ of 0.77 between low coherence and $\Delta m_{v}$ (mean $12.45 \pm 3.25 \%$ ) more than halved from $89.1 \pm 16.1 \mathrm{~cm}$ to $43.8 \pm 4.4 \mathrm{~cm}$ during the same time period. It is probable that this decrease in crop height and subsequent change in scattering geometry contributed to the overall decorrelation. However, it is the $\Delta m_{v}$ that explains most of the variance, corresponding with the fact that over $15 \mathrm{~mm}$ of precipitation was recorded at the time of slave acquisition with all other meteorological variables showing virtually no difference between acquisitions. Excluding the Jul-Sept 2009 L-band pair, the observed linkage between low coherence and $\Delta m_{v}$ is weak. The effects of volume scattering, determined by the inhomogeneity of the crop and the signal penetration depth appeared to dominate the magnitude of decorrelation, in agreement with studies by Blaes and Defourny [59] and Engdahl et al., [56].

\subsection{Coherence and Intensity Change Analysis}

As the soil moisture content increases, the dielectric constant increases and consequently the radar backscatter increases. The presence of vegetation, however, introduces an additional level of complexity. Once the vegetation biomass exceeds a certain limit, dependent on the sensor frequency, the ability of the SAR to sense soil moisture content decreases rapidly $[60,61]$. The backscattering response at various frequencies among different agricultural crops has been documented in several studies [62-65]. As the sensor wavelength increases, so does the dielectric constant of water, permitting higher sensitivity to soil moisture measurements at longer wavelengths (e.g. L-band) [66]. Furthermore, as L-band can penetrate deeper into the vegetation layer to interact with the underlying soil, it has been shown 
Table 6. Correlation of Backscatter Intensity Change $\left(\Delta \sigma^{0}\right)$ and Soil Moisture Change $\left(\Delta m_{v}\right)$

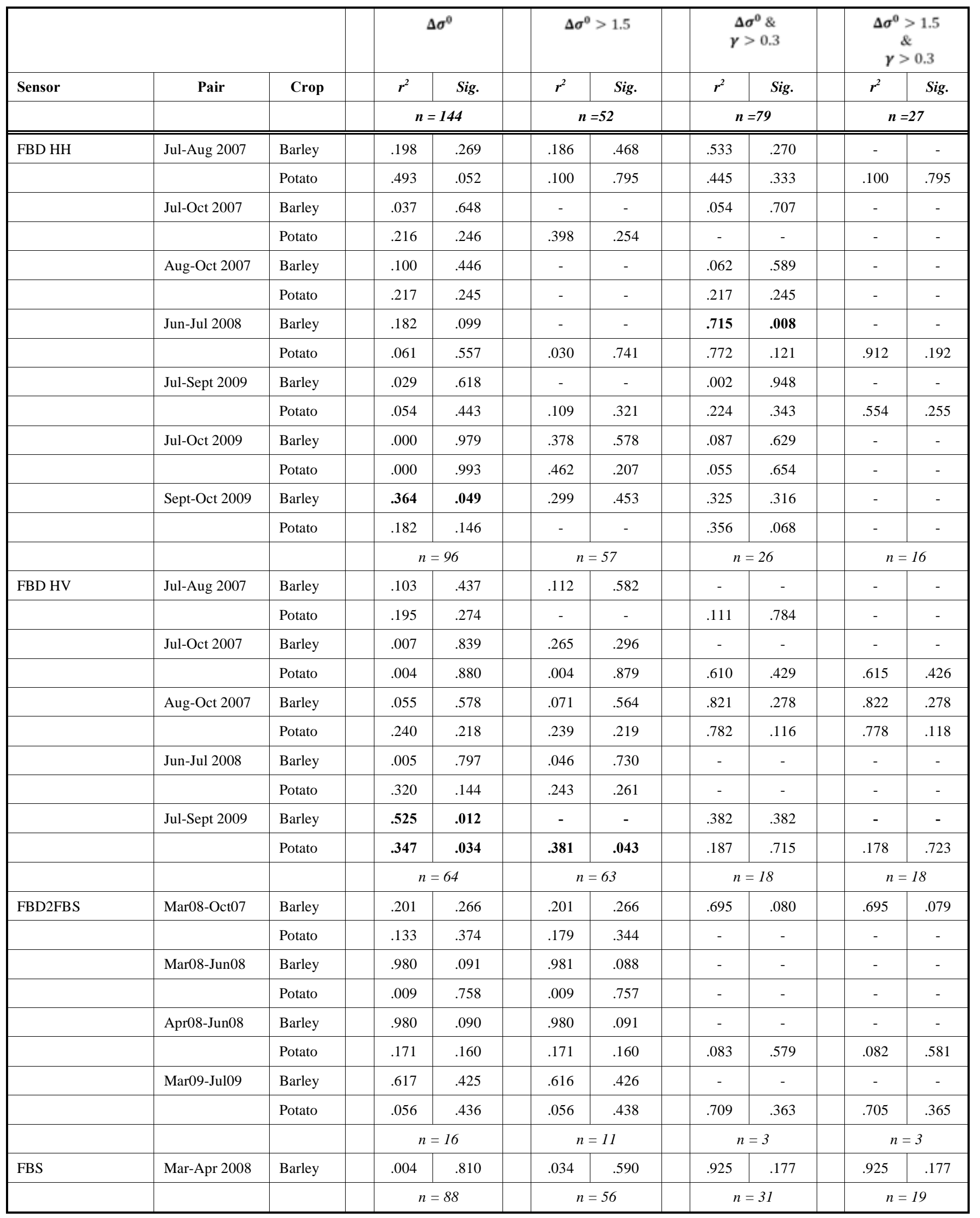


Table 6 Contd....

\begin{tabular}{|c|c|c|c|c|c|c|c|c|c|c|}
\hline \multirow[b]{2}{*}{ ASAR HH } & \multirow[b]{2}{*}{ Jul-Aug 2007} & \multirow[b]{2}{*}{ Barley } & \multicolumn{2}{|c|}{$\Delta \sigma^{0}$} & \multicolumn{2}{|c|}{$\Delta \sigma^{0}>1.5$} & \multicolumn{2}{|c|}{$\begin{array}{c}\Delta \sigma^{0} \& \\
\gamma>0.3\end{array}$} & \multicolumn{2}{|c|}{$\begin{array}{c}\Delta \sigma^{0}>1.5 \\
\& \\
\gamma>0.3\end{array}$} \\
\hline & & & .051 & .589 & - & - & .821 & .278 & - & - \\
\hline & & Potato & .203 & .262 & .822 & .034 & - & - & - & - \\
\hline & Jun-Jul 2008 & Barley & .006 & .769 & .014 & .880 & .154 & .607 & - & - \\
\hline & & Potato & .349 & .123 & .000 & .995 & - & - & - & - \\
\hline & Jul-Oct 2008 & Barley & .008 & .740 & .319 & .056 & .204 & .445 & .806 & .102 \\
\hline & & Potato & .576 & .029 & - & - & - & - & - & - \\
\hline & Jun-Jul 2009 & Barley & .028 & .620 & .052 & .623 & .290 & .461 & .008 & .944 \\
\hline & & Potato & .209 & .116 & .000 & .957 & .127 & .313 & .012 & .792 \\
\hline & & & \multicolumn{2}{|c|}{$n=64$} & \multicolumn{2}{|c|}{$n=17$} & \multicolumn{2}{|c|}{$n=34$} & \multicolumn{2}{|c|}{$n=11$} \\
\hline \multirow[t]{6}{*}{ ASAR HV } & Jul-Aug 2007 & Barley & .341 & .129 & & - & .077 & .722 & - & - \\
\hline & & Potato & .091 & .467 & .745 & .059 & .070 & .830 & .070 & .830 \\
\hline & Jun-Jul 2008 & Barley & .026 & .551 & .522 & .105 & .389 & .134 & - & - \\
\hline & & Potato & .027 & 699 & .514 & .283 & .045 & .733 & .514 & .283 \\
\hline & Jul-Oct 2008 & Barley & .041 & .449 & - & - & .145 & .399 & - & - \\
\hline & & Potato & .002 & .915 & - & - & .002 & .915 & - & - \\
\hline
\end{tabular}

to be sensitive to surface soil moisture under various agricultural crops [67, 68]. Conversely, surface scattering from the underlying soil is minimised at shorter wavelengths (C-band) and volume scattering in the uppermost canopy predominates.

The coherence is less sensitive to changes in soil moisture than backscattered intensity, provided there is not a complete change in soil moisture state between acquisitions. Studies by Wegmüller [33] and Moeremans and Dautrebande [34] showed that the combined use of backscatter intensity and high interferometric coherence had a strong potential for soil moisture determination. To infer the utility of a combined coherence and backscatter intensity approach, a regression analysis was performed to investigate the tendency of $\Delta \sigma^{0}$ to change with soil moisture using the different criteria outlined in section 3.3. The results of this analysis are presented in Table 6. From the available dataset, it is evident that the combination of a $\Delta \sigma^{0}>1.5 \mathrm{~dB} \& \gamma>0.3$ threshold greatly restricts the number of viable pairs. On the one hand, this limits the practicality of the approach but could also be argued to effectively eliminate unreliable pairs and strengthen the analysis. Although a few significant correlations were observed in the other categories $\left(\Delta \sigma^{0}\right.$ correlated with $\Delta m_{v}$ and $\Delta \sigma^{0}>1.5$ correlated with $\Delta m_{v}$ ), their meaning is trivial given that their $\gamma$ was below 0.3 , signaling that the $\Delta \sigma^{0}$ variations were more likely caused by surface roughness or vegetation changes than soil moisture differences (as reported in section 4.1). Moderate to high $\mathrm{R}^{2}$ values, ranging from 0.51 to 0.92 , were found in ten datasets from the $\Delta \sigma^{0}>1.5 \mathrm{~dB} \& \gamma>0.3$ category. Although none of these relationships were statistically significant at the 0.05 level, they represented an improvement in terms of correlation strength and reduction in the probability of error when compared to the original $\Delta \sigma^{0}$ and $\Delta m_{v}$ analysis.
Multitemporal RGB colour composites (Fig. 7) were generated, as in Wegmuller and Werner [69] to aid interpretation of the coherence and intensity images $\left(\Delta \sigma^{0}>1.5 \mathrm{~dB}\right.$ and $\gamma>0.30)$ with high $\mathrm{R}^{2}$ values. The coherence image is displayed in the red channel, the mean backscatter between the two acquisitions in green and backscatter change (ratio) in blue. Water areas always exhibit significant decorrelation and have been masked out. The crop fields used in the study revealed different colours according to their vegetation type, roughness and moisture content. For example, the green appearance of field $\mathrm{C}$ in Fig. (7b) represents high backscatter intensity with low coherence, and low to moderate backscatter intensity change. The same field in Fig. (7c) signifies a strong backscatter intensity change (with low coherence and low backscatter intensity). Field A in Fig. (7h) displays a magenta-bluish colour, representing a medium to low coherence in combination with a moderate backscatter intensity change, indicative of soil moisture change $\left(R^{2} 0.69\right)$. The strong blue appearance of field $\mathrm{C}$ in Fig. (7g) is indicative of a high backscatter intensity change and low coherence associated with the mechanical cultivation of the field between the two acquisition dates. The bright green-yellow area in the lower part of the plots (more pronounced in $\mathrm{HH}$ ) is the town of Cobh (high coherence, high backscatter intensity and low backscatter change). Due to the lower resolution of the C-band pairs (Fig. (7e) and (f)), the individual field boundaries are not as well defined, making their interpretation more difficult. Nonetheless, the magentablue colour of field $\mathrm{C}$ and to a lesser extent, field $\mathrm{A}$ in figure $7(e)$ can be distinguished and represent a soil moisture change $\left(\mathrm{R}^{2}=0.81\right)$ between acquisitions. When dealing with small field sizes such as those used in this study and typical in general of field sizes in Ireland, the benefit of higher resolution SAR data is evident. 

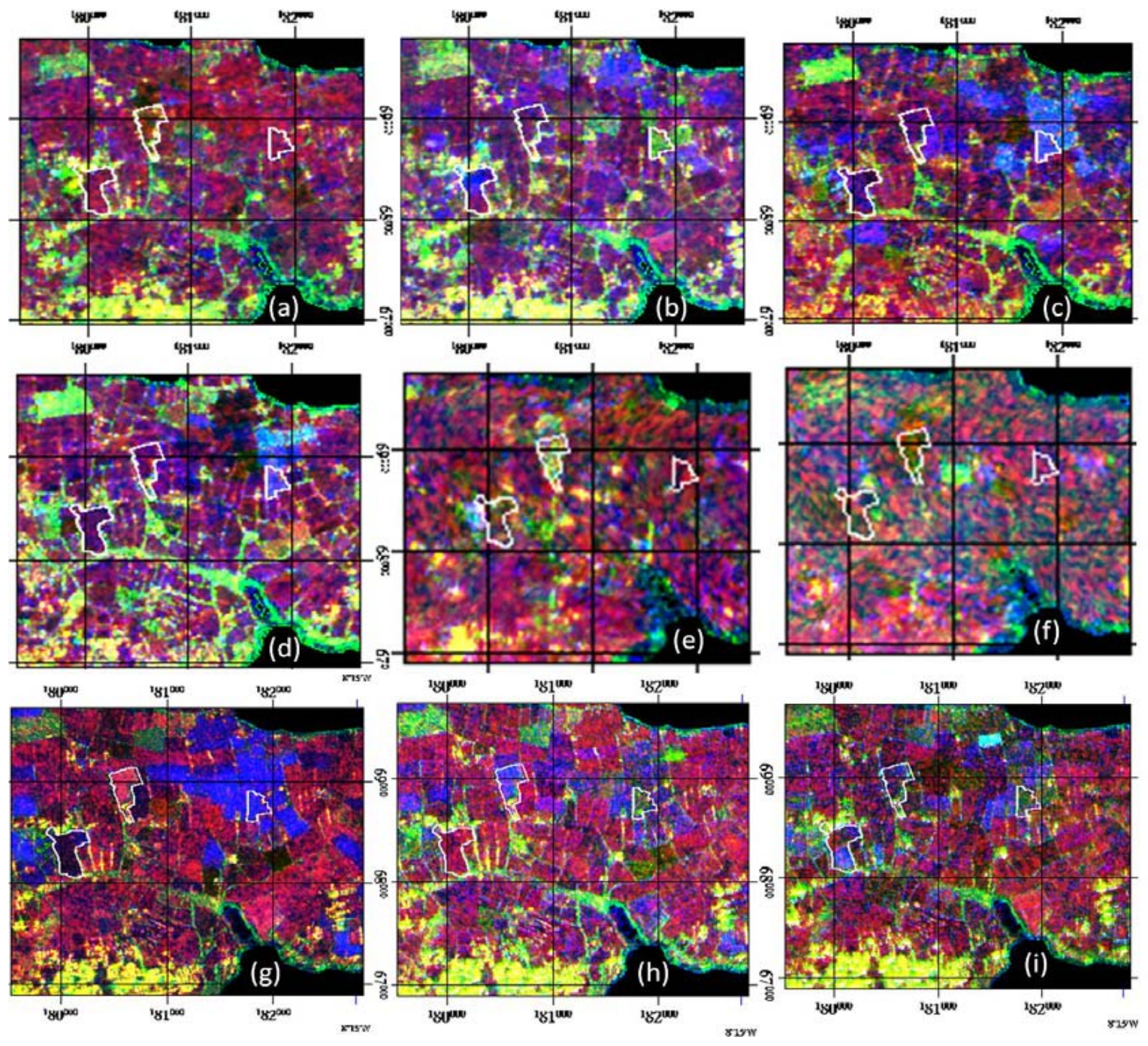

Fig. (7). False colour composites using PALSAR FBD images; (a) $1^{\text {st }}$ June $2008-17^{\text {th }}$ July 2008 , (b) $20^{\text {th }}$ July $2009-4^{\text {th }}$ Sept 2009 , (c) $15^{\text {th }} \mathrm{Jul}-15^{\text {th }}$ Oct 2007 , (d) $30^{\text {th }}$ Aug $-15^{\text {th }}$ Oct 2007, ASAR APS images; (e) $6^{\text {th }}$ July $-19^{\text {th }}$ Oct 2008 , (f) $1^{\text {st }}$ June $-6^{\text {th }}$ July 2008 , PALSAR FBS; (g) $1^{\text {st }}$ Mar $-16^{\text {th }}$ Apr 2008PALSAR mixed mode; (h) $1^{\text {st }}$ Mar $2008-15^{\text {th }}$ Oct 2007 , (i) $4^{\text {th }}$ Mar $2009-20^{\text {th }}$ July 2009 . The coherence image is displayed in the red channel, the mean backscatter between acquisitions in green and backscatter change (ratio) in blue. The study field boundaries are delineated in white.

For a complete analysis, the influence of the plant geometry on the backscattering coefficient must also be taken into account. It has been reported in studies by Ferrazzoli et al., [70], Macelloni et al., [71] and Marliani et al., [72] that backscatter from 'broad' leaved crops (e.g. potatoes) increased with an increase in biomass, whereas backscattering from 'narrow' leaved crops (e.g. barley) showed a constant or decreasing backscatter as the plants grows. The polarisation of the signal also has to be considered, as generally co-polarised waves penetrate the vegetation to a greater extent than cross-polarised. Volume scattering in the vegetation layer causes depolarisation of the signal resulting in backscatter intensity in HV being higher for vegetated areas than for non-vegetated areas. The areas where strong volume scattering effects occurred are well defined in the HV plots in Fig. (7) (e.g. forest in the top left and trees south of field B in Fig. (7c) and $(d))$. Depolarisation was much stronger in broadleaf crop geometries (e.g. potato) than narrow leaf crops (e.g. barley). For example, the average increase in backscatter for the potato crop between $1^{\text {st }}$ June and $17^{\text {th }}$ July 2008 was $3.47 \mathrm{~dB}$ in $\mathrm{HH}$ and 7.46 in $\mathrm{HV}$ polarisation during which time there was an increase in potato height of $\sim 44.3 \mathrm{~cm}$. Over the same time period there was an increase of just $0.04 \mathrm{~dB}$ in $\mathrm{HH}$ and $1.64 \mathrm{~dB}$ in $\mathrm{HV}$ for the barley crop with an average height change of $\sim 53.6 \mathrm{~cm}$. Notwithstanding this, the average change in measured soil moisture of $21.8 \pm$ $4.5 \%$ between the two dates was the largest difference recorded in any of the FBD data pairs and pertinently explained the observed $\mathrm{R}^{2}$ of 0.91 . Since all of the pairs displayed in Table 6 exhibited plant height increases and decreases of some magnitude between acquisitions, (apart from FBD2FBS Mar08-Oct07 and FBS Mar-Apr08), it would be prudent to consider this contribution when interpreting the true cause of the backscatter increase.

\section{CONCLUSIONS AND OUTLOOK}

In this study, the use of repeat-pass C- and L-band InSAR for surface soil moisture change detection was investi- 
gated. Two quite different approaches of using interferometric coherence have been presented. In the first analysis, the link between soil moisture change and decorrelation in SAR coherence images covering agricultural fields was examined. The results indicated that, in very few cases, changes in soil moisture content of $\sim>10 \%$ may be associated with a decrease in coherence. There were certain limitations to this approach that must be recognised. The fact that the soil moisture change must be sufficiently large to reveal a decorrelation effect is of critical importance. As expected, not every pair displayed such large changes. The large time interval between acquisitions, the presence of vegetation and change in weather conditions furthered the intricacy of separating the various sources of temporal decorrelation. The scatterer change associated with the temporal development of the crop was believed to be the predominating source for the pairs analysed in this study. In the second analysis, the sensitivity of sampling site pixels with $\gamma>0.3$ and $\sigma^{0}$ changes of $>1.5 \mathrm{~dB}$ to in-situ measured soil moisture change was investigated. The results indicated that, in several cases, there is a correlation between soil moisture and backscatter intensity changes under both potato and barley crop covers. In these cases, the thresholding technique introduced an improvement in the correlation strengths and increased the reliability of the soil moisture change detection, albeit reducing its practicality from an operational point of view.

The uncertainties involved and the inconsistencies in the results emphasise the need for further research in this area. Results of the present study are not directly comparable with the majority of published studies that used ERS 1/2 Tandem or more recently ERS-ENVISAT pairs [58] due to the longer temporal separation between acquisitions. The main difficulty limiting the implementation of the coherence and intensity approach in this study was the temporal baseline of acquisitions. The results obtained suggest that the use of long-interval repeat-pass coherence is not robust enough to facilitate the routine use of InSAR for agricultural soil moisture monitoring. Future spaceborne C- and L-band SAR sensors with shorter repeat cycles, (e.g. Radarsat Constellation - 12 day repeat cycle, Sentinel-1 - 12 day repeat cycle and the proposed TerraSAR-L mission - 14 day repeat cycle) will overcome the limitation of current sensors with long repeat cycles and should provide more useable datasets. In the interim, alternative options for soil moisture change detection include the use of Differential SAR interferometry (DInSAR) and Polarimetric SAR Interferometry (PolInSAR). Since first being proposed by Gabriel et al., [73], very few studies have investigated the use of DInSAR for soil moisture monitoring [74-76] while the constraint of vegetation cover may be overcome in future studies with the use of Pol-InSAR [77] as shown by Hajnsek et al., [51, 78] to have the potential to operationally deliver biophysical information over vegetated surfaces.

\section{CONFLICT OF INTEREST}

None declared.

\section{ACKNOWLEDGEMENTS}

The authors would like to thank the European Space Agency (ESA) for providing the SAR data under AOIreLux project ID4406. The authors would also like to acknowledge the Irish Environmental Protection Agency (EPA) for supporting this research through the Science, Technology, Research and Innovation for the Environment (STRIVE) Programme, financed by the Irish Government under the National Development Plan (NDP) 2007-2013.

\section{REFERENCES}

[1] Yeh T, Wetherald R, Manabe S. The effect of soil moisture on the short-term climate and hydrology change - A numerical experiment. Mon Weather Rev 1984; 112(3): 474-90.

[2] DeLiberty TL, Legates DR. Interannual and seasonal variability of modelled soil moisture in Oklahoma. Int J Climatol 2003; 23(9): 1057-86.

[3] Eswaran H, Berg E, Reich P. Organic carbon in soils of the world. Soil Sci Soc Am J 1993; 57(1): 192-4.

[4] Davidson E, Janssens I. Temperature sensitivity of soil carbon decomposition and feedbacks to climate change. Nature 2006; 440(7081): 165-73.

[5] Schjonning P, Thomsen I, Moldrup P, Christensen B. Linking soil microbial activity to water-and air-phase contents and diffusivities. Soil Sci Soc Am J 2003; 67(1): 156-65.

[6] Chen MM, Zhu YG, Su YH, Chen BD, Fu BJ, Marschner P Effects of soil moisture and plant interactions on the soil microbial community structure. Eur J Soil Biol 2007; 43(1): 31-8.

[7] Verstraeten W, Veroustraete F, Feyen J. Assessment of evapotranspiration and soil moisture content across different scales of observation. Sensors 2008; 8(1): 70-117.

[8] Xu L, Baldocchi D, Tang J. How soil moisture, rain pulses, and growth alter the response of ecosystem respiration to temperature. Global Biogeochem Cycles 2004; 18(4): 1-10

[9] Eswaran H, Van den Berg E, Reich P, Kimble J. Global soil carbon resources. In: Lai R, Kimble J, Levine E, Stewart BA, Eds. Soils and Global Change. Florida, USA: CRC Press 1995; pp. 27-43.

[10] Raich J, Potter C. Global patterns of carbon dioxide emissions from soils. Global Biogeochem Cycles 1995; 9(1): 23-36.

[11] Wigley T, Schimel D. The Carbon Cycles.UK: Cambridge University Press 2000

[12] Barrett B, Dwyer E, Whelan P. Soil moisture retrieval from active spaceborne microwave observations: An evaluation of current techniques. Remote Sens 2009; 1(3): 210-42.

[13] Oh Y, Sarabandi K, Ulaby FT. An empirical model and an inversion technique for radar scattering from bare soil surfaces. IEEE Trans Geosci Remote Sens 1992; 30(2): 370-81.

[14] Dubois PC, Van Zyl J, Engman T. Measuring soil moisture with imaging radars. IEEE Trans Geosci Remote Sens 1995; 33(4): 91526.

[15] Fung AK, Li Z, Chen KS. Backscattering from a randomly rough dielectric surface. IEEE Trans Geosci Remote Sens 1992; 30(2): 356-69.

[16] Griffiths H. Interferometric synthetic aperture radar. Electron Commun Eng J 1995; 7(6): 247-56.

[17] Bamler R, Hartl P. Synthetic aperture radar interferometry. Inverse Probl 1998; 14(4): R1-R54.

[18] Bürgmann R, Rosen P, Fielding E. Synthetic aperture radar interferometry to measure Earth's surface topography and its deformation. Annu Rev Earth Planet Sci 2000; 28(1): 169-209.

[19] Rosen P, Hensley S, Joughin I, et al. Synthetic aperture radar interferometry. Proc IEEE 2000; 88(3): 333-82.

[20] Zebker HA, Villasenor J. Decorrelation in interferometric radar echoes. IEEE Trans Geosci Remote Sens 1992; 30(5): 950-9.

[21] Bamler R, Just D, Eds. Phase statistics and decorrelation in SAR interferograms. Proceedings of the IEEE International Geoscience and Remote Sensing Symposium (IGARSS 93); 1993 18-21 August; Tokyo, Japan.

[22] Morley J, Muller J, Madden S, Eds. Wetland monitoring in Mali using SAR interferometry. Proceedings of the Fringe 96 Workshop; 199730 September - 2 October 1996; Zurich, Switzerland: European Space Agency (ESA) ESA-SP-406.

[23] Lanari R, Fornaro G, Riccio D, et al. Generation of digital elevation models by using SIR-C/X-SARmultifrequency two-pass interferometry: the Etna case study. IEEE Trans Geosci Remote Sens 1996; 34(5): 1097-114.

[24] Massonnet D, Rossi M, Carmona C, et al. The displacement field of the Landers earthquake mapped by radar interferometry. Nature 1993; 364(6433): 138-42. 
[25] Peltzer G, Rosen P. Surface displacement of the 17 May 1993 Eureka Valley, California, earthquake observed by SAR interferometry. Science 1995; 268(5215): 1333.

[26] Carnec C, Fabriol H. Monitoring and modeling land subsidence at the Cerro Prieto geothermal field, Baja California, Mexico, using SAR interferometry. Geophys Res Lett 1999; 26(9): 1211-4.

[27] Colesanti C, Wasowski J. Investigating landslides with space-borne Synthetic Aperture Radar (SAR) interferometry. Eng Geol 2006; 88(3-4): 173-99.

[28] Rosen P, Hensley S, Zebker H, Webb F, Fielding E. Surface deformation and coherence measurements of Kilauea Volcano, Hawaii, from SIR-C radar interferometry. J Geophys Res 1996; 268: $1333-336$

[29] Lu Z, Freymueller J. Synthetic aperture radar interferometry coherence analysis over Katmai volcano group Alaska. J Geophys Res 1998; 103: 29,887-94.

[30] Goldstein R, Engelhardt H, Kamb B, Frolich R. Satellite radar interferometry for monitoring ice-sheet motion: application to an antarctic ice stream. Science 1993; 262: 1525-30.

[31] Rignot E, Kanagaratnam P. Changes in the velocity structure of the Greenland Ice sheet. Science 2006; 311(5763): 986-90.

[32] Rignot E, Bamber J, Van den Broeke M, et al. Recent Antarctic ice mass loss from radar interferometry and regional climate modelling. Nat Geoscience 2008; 1(2):106-10.

[33] Wegmüller U, Ed. Soil moisture monitoring with ERS SAR interferometry. Proceedings of the Third ERS Symposium: Space at the Service of our Environment ESA-SP-414; 1997; March 1721 Florence.

[34] Moeremans B, Dautrebande S. Soil moisture evaluation by means of multi-temporal ERS SAR PRI images and interferometric coherence. J Hydrol 2000; 234(3-4): 162-9.

[35] Lu Z, Meyer DJ. Study of high SAR backscattering caused by an increase of soil moisture over a sparsely vegetated area: implications for characteristics of backscattering. Int J Remote Sens 2002; 23(6): 1063 - 74.

[36] Dobson MC, Ulaby FT. Active microwave soil moisture research. IEEE Trans Geosci Remote Sens 1986; 24(1): 23-36.

[37] Srivastava SK, Jayaraman V. Relating interferometric signature of repeat pass ERS-1 SAR signals to dynamic land cover changes. Acta Astronaut 2001; 48(1): 37-44.

[38] Luo X, Askne J, Smith G, Dammert P. Coherence characteristics of radar signals from rough soil. Prog Electromagn Res 2001; 31: 6988.

[39] Weydahl DJ. Analysis of ERS SAR coherence images acquired over vegetated areas and urban features. Int J Remote Sens 2001; 22(14): 2811-30.

[40] Nesti G, Tarchi D, Rudant JP, Eds. Decorrelation of backscattered signal due to soil moisture changes. Proceedings of the IEEE Int Geosci Remote Sens Symposium 1995; Florence, Italy.

[41] Nesti G, Tarchi D, Bedidi A, et al, Eds. Phase shift and decorrelation of radar signal related to soil moisture changes. Proceedings of the Retrieval of Bio- and Geo-Physical Parameters from SAR Data for Land Applications Workshop, 1998. 21-23 October; ESTEC: Netherlands 1998 ESASP.

[42] Srivastava HS, Patel P, Navalgund RR. Incorporating soil texture in soil moisture estimation from Extended Low-1 beam mode Radarsat-1 SAR data. Int J Remote Sens 2006; 27(12): 2587- 98.

[43] Rosenqvist A, Milne AK, Zimmermann R. Systematic data acquisitions-a prerequisite for meaningful biophysical parameter retrieval? IEEE Trans Geosci Remote Sens 2003; 41(7): 1709-11.

[44] Gatelli F, Guarnieri A, Parizzi F, Pasquali P, Prati C, Rocca F. The wavenumber shift in SAR interferometry. IEEE Trans Geosci Remote Sens 1994; 32(4): 855-65.

[45] Rodriguez E, Martin J, Eds. Theory and design of interferometric synthetic aperture radars. Proc Inst Electr Eng F 1992; 139: 147-59.

[46] De Grandi G, Leysen M, Lee J, Schuler D, Eds. Radar reflectivity estimation using multiple SAR scenes of the same target: technique and applications. Proceedings of the International Geoscience and Remote Sensing Symposium (IGARSS'97); 1997 3-8 August; Singapore.

[47] OSi. The Irish Grid - A Description of the Co-ordinate Reference System used in Ireland. Dublin, Ireland: Ordnance Survey Ireland; 1996 [26th Jan 2010]; Available from: http://www.osi.ie/en/alist/publications-papers.aspx.

[48] Smith G, Dammert P, Askne J, Eds. Decorrelation mechanisms in C-band SAR interferometry over boreal forest.Franceschetti G,
Oliver CJ, Robertone FS, Tajbaklash S, Eds. Proceedings of SPIE, Microwave sensing and synthetic aperture radar; 1996. vol. 2958: pp. 300-10.

[49] Zebker H, Rosen P, Earth J. Atmospheric artifacts in interferometric SAR surface deformation and topographic maps. J Geophys Res Solid Earth 1997; 102(B4): 7547-63.

[50] Drezet P, Quegan S. Environmental effects on the interferometric repeat-pass coherence of forests. IEEE Trans Geosci Remote Sens 2006; 44(4): 825-37.

[51] Hajnsek I, Jagdhuber T, Schon H, Papathanassiou KP. Potential of Estimating Soil Moisture Under Vegetation Cover by Means of PolSAR. IEEE Trans Geosci Remote Sens 2009; 47(2): 442-54.

[52] Hagberg J, Ulander L, Askne J. Repeat-pass SAR interferometry over forested terrain. IEEE Trans Geosci Remote Sens 1995; 33(2): $331-40$.

[53] Balzter H. Forest mapping and monitoring with interferometric synthetic aperture radar (InSAR). Prog Phys Geog 2001; 25(2): 159-77.

[54] Askne J, Santoro M, Smith G, Fransson J. Multitemporal repeatpass SAR interferometry of boreal forests. IEEE Trans Geosci Remote Sens 2003; 41(7): 1540-50.

[55] Srivastava HS, Patel P, Sharma Y, Navalgund RR. Detection and density mapping of forested areas using SAR interferometry technique. Int J Geoinformatics 2007; 3(2): 1-10.

[56] Engdahl ME, Borgeaud M, Rast M. The use of ERS-1/2 Tandem interferometric coherence in the estimation of agricultural crop heights. IEEE Trans Geosci Remote Sens 2001; 39(8): 1799-806.

[57] Srivastava HS, Patel P, Navalgund RR. Application potentials of synthetic aperture radar interferometry for land-cover mapping and crop-height estimation. Curr Sci 2006; 91(6): 783-8.

[58] Santoro M, Wegmuller U, Askne JIH. Signatures of ERS-Envisat Interferometric SAR Coherence and Phase of Short Vegetation: An Analysis in the Case of Maize Fields. IEEE Trans Geosci Remote Sens 2010; 48(4): 1702-13.

[59] Blaes X, Defourny P. Retrieving crop parameters based on tandem ERS 1/2 interferometric coherence images. Remote Sens Environ 2003; 88(4): 374-85.

[60] Wang Y, Kasischke E, Melack J, Davis F, Christensen Jr N. The effects of changes in loblolly pine biomass and soil moisture on ERS-1 SAR backscatter. Remote Sens Environ 1994; 49(1): 25-31.

[61] Waring R, Way J, Hunt Jr E, et al. Imaging radar for ecosystem studies. Bioscience 1995; 45(10): 715-23.

[62] Saich P, Borgeaud M. Interpreting ERS SAR signatures of agricultural crops in Flevoland, 1993-1996. IEEE Trans Geosci Remote Sens 2000; 38(2): 651-7.

[63] De Roo R, Du Y, Ulaby F, Dobson M. A semi-empirical backscattering model at L-band and C-band for a soybean canopy with soil moisture inversion. IEEE Trans Geosci Remote Sens 2001; 39(4): 864-72.

[64] Ferrazzoli P, Ed. SAR for agriculture: advances, problems and prospects. Proceedings of the Third International Symposium on Retrieval of Bio-and Geophysical Parameters from SAR Data for Land Applications, 11-14 September; 2002; Sheffield: UK 2002. ESASP-475.

[65] Del Frate F, Schiavon G, Solimini D, Borgeaud M, Hoekman DH, Vissers MAM. Crop classification using multiconfiguration C-band SAR data. IEEE Trans Geosci Remote Sens 2003; 41(7): 1611-9.

[66] Van der Meer F. Can we map swelling clays with remote sensing? Int J App Earth Obs Geoinform 1999; 1(1): 27-35.

[67] Schmullius C, Furrer R. Frequency dependence of radar backscattering under different moisture conditions of vegetationcovered soil. Int J Remote Sens 1992; 13(12): 2233-45.

[68] Schmullius C, Furrer R. Some critical remarks on the use of Cband radar data for soil moisture detection. Int J Remote Sens 1992; 13(17): 3387-90.

[69] Wegmuller U, Werner C, Eds. Farmland monitoring with SAR interferometry. Proc IGARSS 1995 July 10-14; Florence, Italy.pp. 544-46

[70] Ferrazzoli P, Solimini D, Luzi G, Paloscia S. Model analysis of backscatter and emission from vegetated terrains. J Electromagn Wave 1991; 5(2): 175-93.

[71] Macelloni G, Paloscia S, Pampaloni P, Marliani F, Gai M. The relationship between the backscattering coefficient and the biomass of narrow and broad leaf crops. IEEE Trans Geosci Remote Sens 2001;39(4): 873-84. 
[72] Marliani F, Paloscia S, Pampaloni P, Kong J. Simulating coherent backscattering from crops during the growingcycle. IEEE Trans Geosci Remote Sens 2002; 40(1): 162-77.

[73] Gabriel AK, Goldstein R, Zebker HA. Mapping small elevation changes over large areas: Differential radar interferometry. J. Geophys Res 1989; 94(B7): 9183-91.

[74] Nolan M, Fatland DR. Penetration depth as a DInSAR observable and proxy for soil moisture. IEEE Trans Geosci Remote Sens 2003; 41(3): 532-7.

[75] Nolan M, Fatland DR, Hinzman L. DInSAR measurement of soil moisture. IEEE Trans Geosci Remote Sens 2003; 41(12): 2802-13.
[76] Khadhra K, Nolan M, Börner T, Hounam D, Chandra M, Eds. Phase Sensitivity To Soil Moisture In Controlled Anechoic Chamber: Measurements and First Results. German Microwave Conference - GeMiC 2006; 2006 28-30 March; Karlsruhe, Germany.

[77] Cloude SR, Papathanassiou KP. Polarimetric SAR interferometry. IEEE Trans Geosci Remote Sens 1998; 36(5): 1551-65.

[78] Hajnsek I, Pottier E, Cloude SR. Inversion of surface parameters from polarimetric SAR. IEEE Trans Geosci Remote Sens 2003; 41(4): $727-44$

Received:April 01, 2012

(c) Barrett et al.; Licensee Bentham Open.

This is an open access article licensed under the terms of the Creative Commons Attribution Non-Commercial License (http://creativecommons.org/licenses/by-nc/3.0/) which permits unrestricted, non-commercial use, distribution and reproduction in any medium, provided the work is properly cited. 